\title{
Adobes y la organización del trabajo en la costa norte del Perú
}

\section{Howard I. Tsai}

Universidad de Michigan

Howard I. Tsai, "Adobe Bricks and Labor Organization

on the North Coast of Peru," Andean Past 10 (2012): 133-169.

Traducido por Juan R. Hernández García

\section{INTRODUCCIÓN}

Los arqueólogos que estudian monumentos muchas veces estiman el número de personas y el tiempo necesario para la construcción de un proyecto particular. Sin embargo, menos veces investigan la organización del trabajo, cómo se dividió y subdividió a un grupo de trabajadores, cómo se les asignó las mismas o diferentes tareas, y cómo se les dio crédito y se documentó dicho trabajo. Este tipo de estudio es crucial para entender Estados antiguos ya que revelan relaciones entre los trabajadores, funcionarios y la élite. Estudiando los cambios a través del tiempo de la organización del trabajo, podemos demostrar la evolución de la administración de la mano de obra en el momento en que los Estados tempranos se convierten en imperios.

En este artículo investigo la mano de obra en la costa norte del Perú, presentando datos sobre los adobes en dos sitios arqueológicos: la Huaca de la Luna y Farfán (figs. 1 y 2). En la Huaca de la Luna (Unidad 16, Moche IV, 400-700 d. C.), confirmo observaciones previas hechas por Hastings y Moseley (1975) de que los adobes de igual tamaño y con las mismas marcas de fabricante fueron colocados juntos en el mismo segmento de construcción. En cambio, los adobes de Farfán (ocupación chimú, 1310-1460 d. C.) no contienen marcas de fabricante, y adobes de diversos tamaños se encuentran en la misma parte de una pared. Si la manufactura y construcción de adobe son útiles para inferir la organización de la mano de obra (Cavallaro y Shimada 1988; Hastings y Moseley 1975; Kolata 1978, 164; Moseley 1975; Shimada 1997), entonces estos 


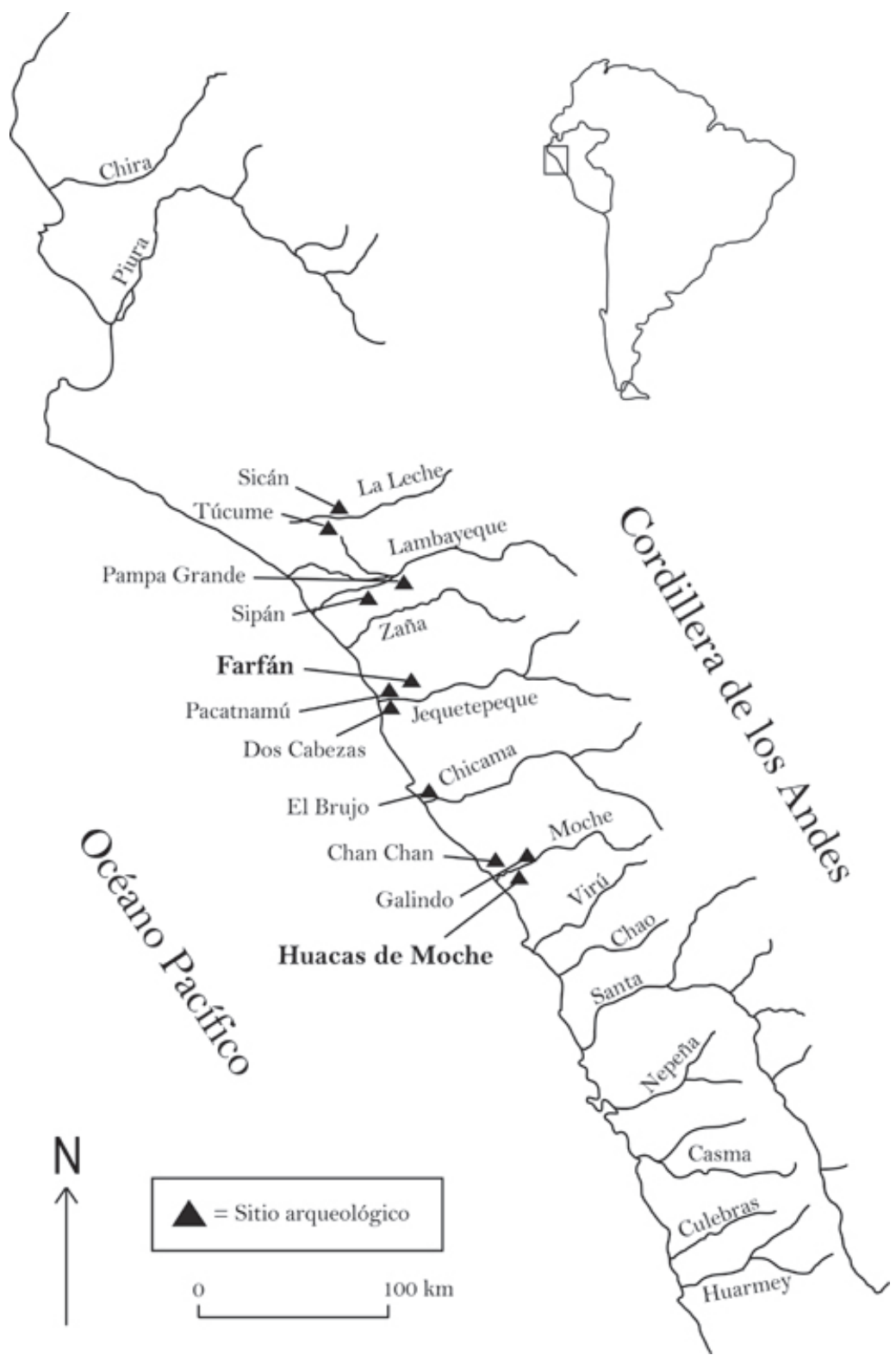

Figura 1. Mapa de la costa norte del Perú. Los sitios arqueológicos discutidos en este artículo están indicados con triángulos. 


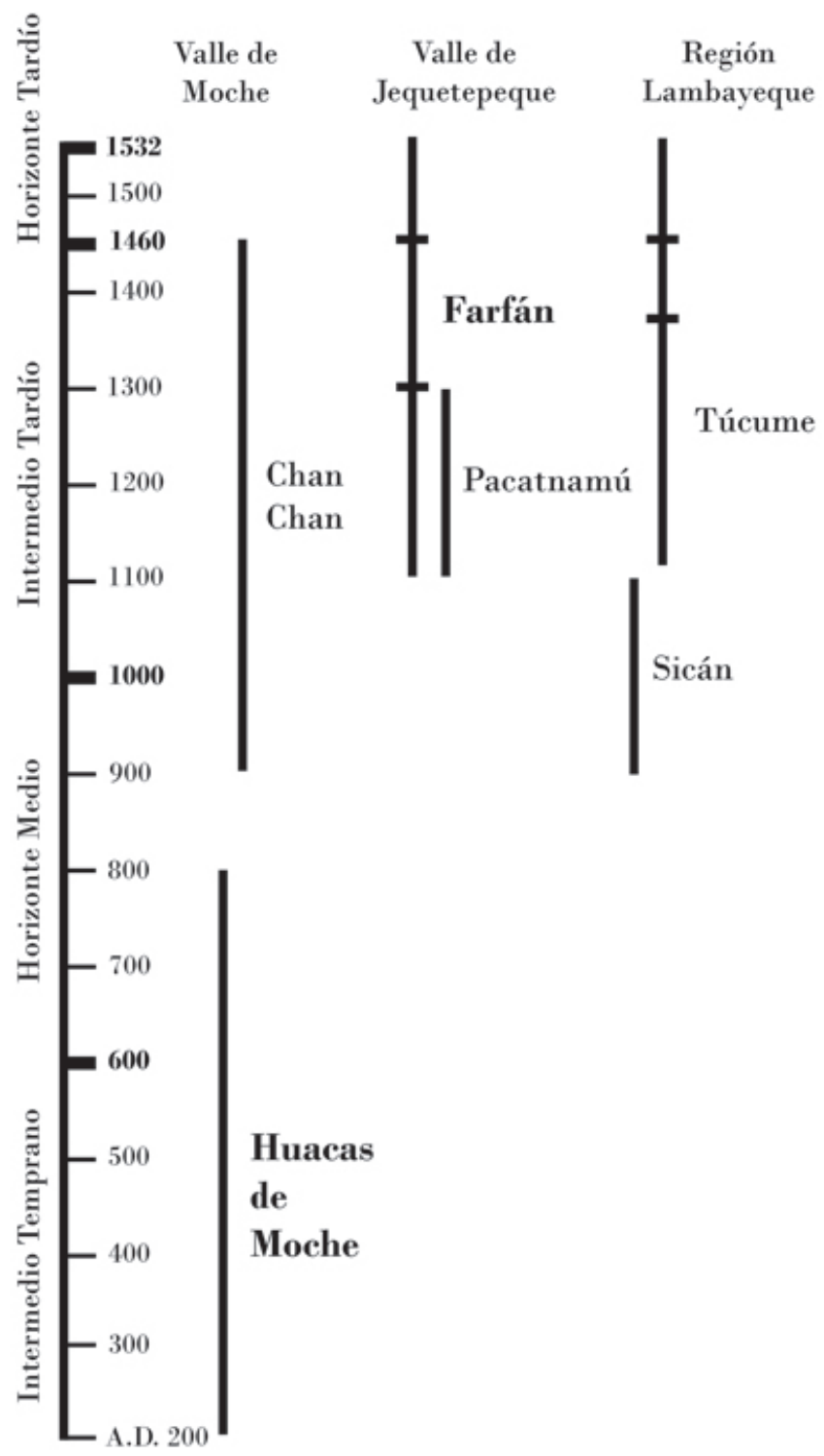

Figura 2. Cronología de algunos de los sitios mencionados en este artículo. 
patrones sugieren que el sistema mochica de organización y registro de las tareas del trabajo de los obreros había desaparecido para el tiempo de los chimú.

\section{HISTORIA CULTURAL DE LA COSTA NORTE DEL PERÚ: 100-1470 D. C.}

Los moche o mochicas fundaron uno de los primeros Estados en los Andes, surgiendo en la costa norte del Perú (Stanish 2001, 55). Algunos investigadores han planteado la hipótesis de la existencia de al menos dos Estados moche entre los siglos II y VIII d. C.: el Estado mochica sureño, centrado en el valle de Moche, y el Estado norteño mochica, en la región Lambayeque (Billman 2002, 372-373; Castillo y Donnan 1994; Shimada 1994, 78-87). En la capital del Estado sureño se construyeron dos pirámides grandes de adobe, la Huaca del Sol y la Huaca de la Luna, la primera midiendo aproximadamente 342 por 159 m, llegando a una altura de $40 \mathrm{~m}$, y conformada por más de 143 millones de adobes (Hastings y Moseley 1975, 196-197). El área entre ambas pirámides era una "zona urbana" repleta de residencias, calles y plazas. Durante la época de mayor apogeo del Estado sureño mochica, entre los años 300 y 700 d. C. (fases Moche III y IV), la capital llegó a su mayor tamaño con al menos 10000 personas viviendo dentro de un radio de cinco kilómetros (Chapdelaine 2003, 276).

Durante el Horizonte Medio (600-1000 d. C.) aparecieron nuevos centros urbanos, incluyendo Galindo, localizado solamente $7 \mathrm{~km}$ al noreste de las Huacas de Moche, y Pampa Grande en el valle Lambayeque, a unos $160 \mathrm{~km}$ al norte. Las fechas radiocarbónicas demuestran que las Huacas del Moche (Chapdelaine 2000, 137), Galindo (Lockhard 2008, 279) y Pampa Grande (Shimada 1994, 4) coexistieron a través del siglo VII d. C. Ya en el 800 d. C. todos estos centros urbanos habían sido abandonados, o al menos dejaron de ser centros importantes de población. Las razones de estas transformaciones aún permanecen inciertas. Algunas de las causas sugeridas son inundaciones y sequías (Moseley 2001, 223-225), agitación social interna (Bawden 1996, 271-275) y la conquista por parte de los wari, un Estado de las zonas serranas cuya capital se encontraba a unos $700 \mathrm{~km}$ (Collier 1955, 136-137; Willey 1953, 398). Esta última hipótesis de que los Estados moche fueron conquistados por los wari no es apoyada por la evidencia arqueológica (Donnan y Mackey 1978, 213; Wilson 1988, 334-335).

Nuevos Estados, y eventualmente un imperio, surgieron en la costa norte de Perú durante el periodo Intermedio Tardío. En el valle La Leche, el Estado sicán, con su capital Batán Grande o Sicán, prosperó entre los años 900 y 1100 d. C., un periodo conocido como Sicán Medio (Shimada 2000, 51-61). Sicán fue el centro primordial de un asentamiento jerárquico de cuatro niveles (ibíd., 61), y en su área central, el Precinto de Sicán, existían más de una docena de huacas o pirámides de adobe. Más adelante los templos al tope de las pirámi- 
des en Sicán fueron quemados y el lugar fue abandonado. Un nuevo centro, Túcume o El Purgatorio (Sandweiss 1995), surgió durante el siguiente periodo (Sicán Tardío, 1100-1360 d. C.).

Mientras Sicán florecía en el norte, los chimú, o el Reino de Chimor (900$1470 \mathrm{~d}$. C.), comenzaron a construir una ciudad llena de palacios, residencias y talleres de trabajo en el valle Moche (Topic y Moseley 1983). Esta ciudad, ahora conocida como el sitio arqueológico Chan Chan, fue el hogar de entre 30000 y 40000 personas, y cubría un espacio de algunos $20 \mathrm{~km}^{2}$, con un centro urbano de $6 \mathrm{~km}^{2}$ (Moore y Mackey 2008, 784). Chimor comenzó su campaña militar alrededor del año 1310 d. C., conquistando otros Estados costeños de los valles de Jequetepeque, Casma y Lambayeque. Tucumé cayó ante los conquistadores chimú entre los años 1360 y $1400 \mathrm{~d}$. C.

La naturaleza militar de la expansión de Chimor fue recordada a través de historias orales documentadas por los cronistas españoles algunos dos siglos después (Cabello Valboa [1586] 1951, 329; Calancha [1638] 1977, 1227). La evidencia arqueológica sobre la conquista de la región por los chimú consiste de complejos rectangulares parecidos a los palacios o ciudadelas de Chan Chan, pero muy diferentes a los sitios locales, no chimú. Ya en el año $1460 \mathrm{~d}$. C. el Imperio chimú controlaba un área de más de $600 \mathrm{~km}$, de norte a sur, a lo largo de la costa del Perú. La caída de Chimor fue también documentada por los cronistas españoles, que proveyeron historias (algunas de ellas contradictorias) de la conquista por parte de los incas, el traslado del rey chimú a Cusco y la división del Imperio chimú en provincias pequeñas (Hart 1983, 106-116; Rowe 1948, 42-46).

\section{LOS ADOBES Y LA INVESTIGACIÓN DE LA ORGANIZACIÓN DE TRABAJO}

Testimonios españoles del siglo XVI describen los derechos de los curacas, o señores nativos andinos, para requerir mano de obra y servicios de sus súbditos (Hart 1983, 175-176; Rowe 1946, 261). De acuerdo con Moseley (1975), el reclutamiento y la administración de los trabajadores en la costa norte del Perú se pueden trazar al tiempo de los mochicas. En la capital moche, las masivas pirámides - la Huaca de la Luna y la Huaca del Sol- se construyeron en segmentos, o sea, columnas de adobes separadas y no adheridas por mortero (Kroeber 1930, 61). Algunos de los ladrillos tenían alguna marcación o símbolo de sus fabricantes (una línea, un punto, etc.) grabado en la superficie del adobe cuando estaba aún húmedo. Se han encontrado más de 100 marcaciones diferentes. En cada uno de los segmentos, la mayoría (85-95 por ciento) de los adobes tiene un solo tipo de marca de fabricante. Los adobes del mismo segmento tienden también a tener las mismas dimensiones y están compuestos 
del mismo tipo de suelo (Hastings y Moseley 1975, 197-198). Otros sitios del periodo moche que incluyen adobes marcados son Pampa Grande (Shimada 1994, 162-166), El Brujo (Franco, Gálvez y Vásquez 1994, 160-161), Galindo (Lockard 2008, 287-289), Huaca Vichanzao (Pérez 1994, 241-246) y Dos Cabezas (Donnan 2007, figs. 2.3 y 2.11). Algunas de las marcaciones eran comunes y pueden encontrarse en varios sitios, mientras otras marcaciones son únicas y se pueden encontrar solamente en uno de los sitios arqueológicos (Lockard 2008, 288; Pérez 1994, 244).

Moseley $(1975,192)$ propuso que cada marca de fabricantes representaba a un grupo social específico, posiblemente a un grupo de trabajadores o a una comunidad (fig. 3). La marcación de fabricantes no pudo haber representado a un solo individuo porque (1) algunas de las marcas persistieron por más de un siglo y (2) cien individuos no podían haber producido los 143 millones de ladrillos necesarios para la construcción de la Huaca del Sol (Hastings y Moseley 1975, 197; Moseley 1975, 192). Por lo tanto, el Estado moche tuvo que haber reclutado grupos de trabajadores, como se puede ver representado en las diversas marcas de fabricantes encontradas en la construcción de ambas pirámides.

Unos dos siglos después, un patrón diferente de producción de adobes caracterizó a la región de Chan Chan, la capital del Imperio chimú. Los adobes de Chan Chan no tenían las marcas de fabricantes, y en cualquiera de las estructuras los adobes estaban hechos del mismo suelo y "parecen como si fueron hechos en el(los) mismo(s) molde(s)" (Kolata 1978, 163). Debido a este contraste entre Chan Chan y las dos huacas de Moche, Kolata (ibíd., 164) sugirió que "el método para organizar la mano de obra para la construcción [en Chan Chan] era diferente del usado en la construcción de las pirámides moche”.

El estudio de Shimada (1997) de las estructuras de adobe en la región de Lambayeque lo llevó a sugerir que la organización de la mano de obra había cambiado a través del tiempo. En Sipán, un sitio del periodo Moche III (ca. 300 d. C.) en el valle Lambayeque, los montículos de adobe fueron construidos en segmentos, similares a los encontrados en las Huacas de Moche (Meneses y Chero 1994,182-183). Sin embargo, las estructuras de adobe del periodo Moche V (550-750 d. C.) en el sitio arqueológico Pampa Grande diferían de anteriores patrones de construcción. Algunos de los segmentos de la construcción en Pampa Grande incluían adobes con marcaciones de diferentes fabricantes. Además, algunos segmentos solamente tenían la marca de un solo grupo de fabricantes, pero los ladrillos eran de diferentes tamaños (Shimada 1994, 162 165).

Durante el periodo del Horizonte Medio (750-1000 d. C.), los métodos de construcción dejaron de seguir los esquemas previos de los moche de construir segmentos individuales, con un solo tipo de marcación y adobes del mismo tamaño. En Sicán, muchas veces un segmento contenía adobes de diferentes tamaños y diferentes marcas de fabricantes (Shimada 1997, 79). Este patrón de 


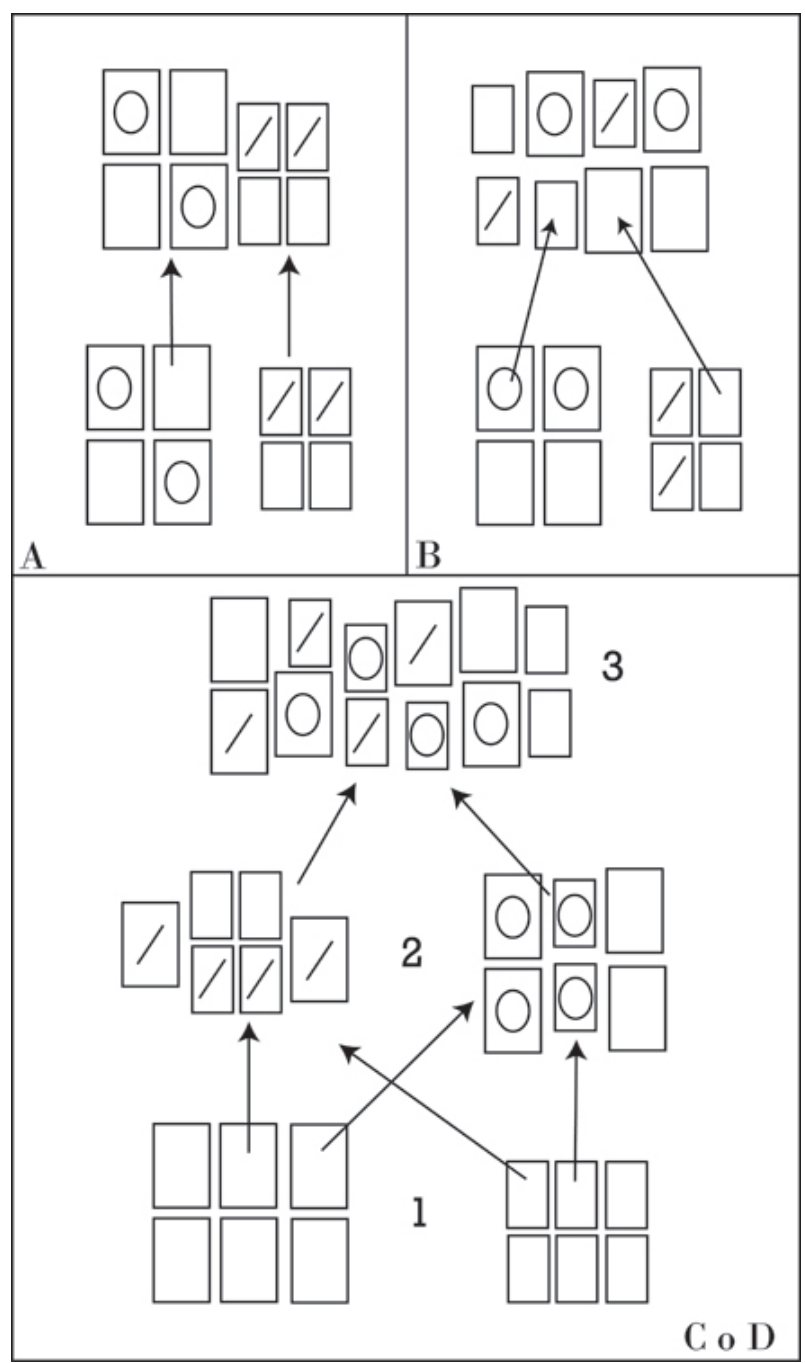

Figura 3. Modelos de construcción de adobes y organización de mano de obra según Cavallaro y Shimada (1988, figs. 11-14). A: Modelo de impuestos de trabajo por Moseley. B: Modelo de impuestos de trabajo diferenciado por tareas. C: Modelo de territorialidad discontinua. D: Modelo de patrocinadores (Modelos C y D producen resultados similares). En el Modelo A, los fabricantes de adobes y los albañiles provienen de la misma comunidad, mientras que en el Modelo $B$ los fabricantes de adobes y los albañiles pertenecen a dos grupos de trabajo separados. En los Modelos C y D, cada taller produce adobes de un solo tamaño (1), los señores o patrocinadores reciben luego los adobes de diversos talleres y graban los adobes con sus propias marcas o "insignias" (2), los adobes son entonces donados para la construcción de un templo (3). 
mezclar diferentes tipos de ladrillos también ocurrió en el sitio arqueológico Túcume, donde "adobes en un segmento específico de una pared varían en tamaño, proporciones, tipos de suelos y marcaciones, y más de la mitad de los adobes están marcados" (Sandweiss 1995, 166). Así, a diferencia de las Huacas de Moche, los sitios de la época posmochica tuvieron segmentos construidos con adobes de diversos tamaños, tipos de suelo y marcas de fabricantes.

Kolata (1978) y Shimada (1997) reconocieron la importancia de estudiar adobes desde una perspectiva diacrónica. Si el tamaño y los métodos de construcción reflejan las formas en que los Estados organizaron la mano de obra, entonces, cualquier cambio en estas variables puede indicar un cambio correspondiente en las formas de organizar la mano de obra. Variaciones en el tamaño y las marcaciones del fabricante en los adobes son el resultado de ciertas decisiones hechas durante la producción de los mismos. Para entender dichas variaciones, necesitamos dividir en varias etapas la producción de adobes, y entonces inferir cómo los patrones en la evidencia arqueológica reflejan las acciones tomadas en cada una de esas etapas de producción.

\section{ETAPAS DE LA PRODUCCIÓN DE ADOBE}

En esta sección presento un breve resumen sobre el proceso de creación del adobe. El propósito de esta discusión es demostrar cómo las diversas etapas en la producción de los adobes afectan la naturaleza cambiante (tamaño, forma, color, etc.) de los ladrillos de barro. La producción de adobes consiste de cuatro etapas: (1) obtener el barro; (2) mezclar el barro con agua y atemperarlo; (3) colocar la mezcla en los moldes de ladrillos; y (4) secar los ladrillos. En la discusión siguiente sobre la producción de adobe, presento mis observaciones sobre la producción de adobe hoy día en el pueblo Moche (mayo-junio 2004) y proveo evidencia arqueológica sobre la producción de adobe prehispánica.

Las adoberías de hoy son grandes depresiones rectangulares en el suelo donde el barro es excavado, mezclado y convertido en adobes. La tierra usada para hacer adobe es una mezcla de arena, limo y arcilla (Brown y Clifton 1978, 139). Antes de que se introdujeran camiones o burros, los fabricantes de adobe obtenían estos materiales cerca de donde se construía la estructura, generalmente a un kilómetro o menos de distancia. En Farfán, el tipo y color (marrón 10YR 5/3 a rojo 7.5YR 5/4; Munsell Color 2000) de la tierra usada para construir los adobes se acerca más al color y tipo del suelo natural cercano a esos adobes. Por ejemplo, los adobes del Complejo I de Farfán contienen gran cantidad de gravillas, e igualmente el suelo alrededor del Complejo I es también bastante rocoso, en comparación a otras áreas.

En el proceso de la mezcla, se añade agua para humedecer la tierra. Es probable que la manufactura de adobe ocurriera entre los meses de noviem- 
bre y abril, cuando hay más agua en el río. Los fabricantes de adobe hoy día siguen una "receta" que dicta los ingredientes del suelo para hacer los adobes. Documenté cuatro de estas recetas en el pueblo Moche. Cada receta tiene proporciones diferentes de arena fina, arena gruesa, tierra y cal. El albañil mezcla el material usando los pies o una pala. Los fabricantes de adobe usan muchas veces paja para atemperar la mezcla.

Moldes de madera son utilizados para manufacturar ladrillos rectangulares. El fabricante vierte la mezcla de suelo en el molde, invierte el molde y lo remueve, dejando el adobe húmedo fuera del mismo. Los ladrillos modernos que son hechos de un solo molde son bastante uniformes. La desviación estándar es de menos de 0.4 centímetros $(\mathrm{n}=61)$. Por lo tanto, si un ladrillo es varios centímetros más grande que otro, es probable que haya sido hecho en un molde diferente.

Durante el periodo Gallinazo (200 a. C. al 200 d. C., periodo Intermedio Temprano), los adobes rectangulares eran hechos de moldes de caña, lo que queda evidenciado por las improntas de caña en los lados de los adobes (Hastings y Moseley 1975, 198). En el siguiente periodo Moche, la mayoría de los adobes tenían lados lisos, aunque algunos aún tenían impresiones de caña (Hastings y Moseley 1975, 198; Moubarac 2002, 59, 69). Los adobes chimú en Farfán tienen lados lisos sin impresión alguna de caña. En vez de ser planos, los topes de la superficie de los ladrillos chimú son muchas veces levemente cóncavos, algunas veces presentando marcas de dedos. Estas marcas sugieren que los fabricantes de adobes en Farfán usaron sus manos para alisar la superficie superior de sus adobes.

Luego de remover los moldes, los fabricantes pueden inscribir una marca en el adobe húmedo (Hastings y Moseley 1975, 198). Los adobes son colocados sobre sus lados, y después de como de una semana, estarán secos y listos para ser usados en alguna construcción (Gillin 1947, 37). Los trabajadores cargan los adobes hasta el lugar de la construcción y los albañiles los colocan usando un mortero de barro para pegarlos. El toque final en el proceso de construcción es una capa de enlucido que cubre la pared y esconde el ladrillo.

\section{MODELOS DE PRODUCCIÓN DE ADOBE Y ORGANIZACIÓN DE TRABAJO}

La producción, transporte y colocación de adobes podrían haber sido hechos por uno o más grupos de trabajadores que realizaban diferentes tareas. Por ejemplo, una comunidad podría haber construido y transportado unos cuantos cientos de ladrillos al lugar de la construcción. Entonces, otro grupo de albañiles, reclutados de otra comunidad, usarían esos ladrillos para construir la pared. Alternativamente, los trabajadores de una misma comunidad podrían ser responsables de todas las tareas, incluyendo la manufactura, transporte y 
colocación de los adobes. Cada fase de la producción y construcción se puede realizar de maneras diferentes, y mediante la evaluación de todas estas posibilidades, tenemos varias permutaciones sobre la secuencia de producción a considerar.

Cavallaro y Shimada (1988) delinearon diferentes modelos para la producción y construcción de adobes, y luego probaron estos modelos usando datos de adobes de los sitios arqueológicos de Sicán y Batán Grande (Fig. 3). En Sicán, descubrieron que muchas veces adobes del mismo tamaño tenían diferentes marcas de fabricantes, lo que los llevó a pensar que el modelo de la "territorialidad discontinua" o modelo del "patrocinador" mejor explicaba los datos (Modelo C o D en la fig. 3). En estos modelos, el "patrocinador" (individuo o comunidad que donaba adobes para la construcción del templo) comisionaba la producción de adobes. El patrocinador, también conocido como curaca, primero recibía adobes de diferentes talleres, marcaba los adobes con la insignia del señor o patrón, y finalmente donaba los adobes para la construcción del templo (Modelo C o D en la fig. 3). Cavallaro y Shimida (ibíd., 98) asumieron que diferentes talleres de adobe producían ladrillos de diferentes tamaños: "El modelo de impuestos de trabajo diferenciado por tareas requeriría el uso de moldes de idéntica forma y tamaño en diversas adoberías, una situación que estimamos poco probable". Más adelante, examino esta suposición usando datos de la Huaca de la Luna. Siguiendo a Cavallaro y Shimida (ibíd.), evalúo cuál de estos modelos describe mejor la producción de adobes en los Estados moche y chimú. Si ambos Estados se pueden caracterizar por tener dos modelos diferentes, esto indicaría que la producción de adobe y la organización de mano de obra cambiaron a través del tiempo. Usando datos de adobes que recolecté en la Huaca de la Luna y Farfán, propongo que el modelo de impuestos en forma de trabajo de Moseley es el mismo que podemos observar en la Huaca de la Luna, y que el de impuestos cobrados por tareas diferentes realizadas, que proponen Carvallo y Shimada (ibíd., 90-92), explica mejor el patrón de variabilidad de adobes en Farfán.

\section{ADOBES DE LA HUACA DE LA LUNA}

La Huaca de la Luna es la menor de las dos pirámides en Moche, llegando a una altura de al menos $20 \mathrm{~m}$ de altura y teniendo más de 50 millones de adobes (Hastings y Moseley 1975, 197). Excavaciones en curso en la Huaca de la Luna, dirigidas desde 1991 por Santiago Uceda y Ricardo Morales, han descubierto evidencia de ofrendas rituales y sacrificios humanos, así como frisos con representaciones de bailadores, guerreros y varias figuras sobrenaturales (Morales 2003; Uceda 1997, 2001; Uceda y Tufinio 2003; Uceda et al. 1994). Excavaciones en el área entre las dos huacas descubrieron una zona urbana densamente 


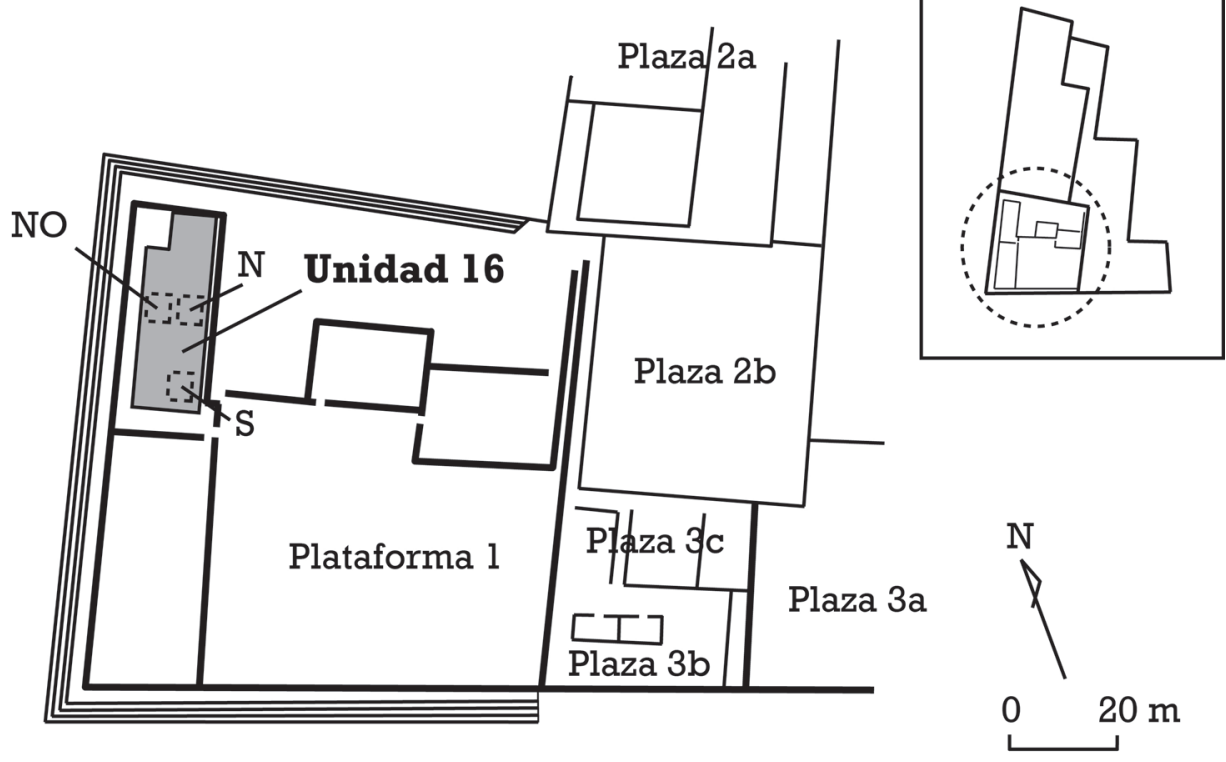

Figura 4. Mapa que muestra la localización de la Unidad 16 en la Huaca de la Luna. Los cuadrados pequeños en líneas entrecortadas indican las áreas en las que los adobes fueron medidos (diagrama basado en los dibujos de Zavaleta 2007, fig. 2).

poblada con múltiples talleres y residencias (Chapdeline 2001; Uceda y Armas 1997; Uceda y Chapdelaine 1998).

Durante el verano del 2004, participé en la excavación de la Unidad 16 en la cima de Huaca de la Luna (fig. 4). La Unidad 16 contenía varios enterramientos. Las cerámicas asociadas a estos enterramientos datan del periodo Moche IV, ca. 400-700 d. C. (Zavaleta 2007, 13). Los adobes de la Unidad 16 son rectangulares y a veces contienen las marcas de fabricantes. La mayoría de los adobes fueron hechos en moldes de madera con lados lisos. Algunos adobes fueron hechos en moldes de caña, como indican las filas de ranuras paralelas que se observan en los lados de los mismos.

Medí el largo, ancho y alto de 95 adobes de la Unidad 16. También documenté la posición en general (norte, noroeste y sur) de los adobes en la unidad (fig. 5). Una marca de los fabricantes (una línea diagonal) fue observada en 14 ladrillos en la esquina norte (fig. 6). Sin embargo, la muestra es muy limitada, especialmente si se contrasta con el número de adobes estudiados en Farfán. He decidido presentar estos datos porque el patrón que encontré difiere drásticamente de cualquier muestra de Farfán. En otras palabras, ninguna muestra 


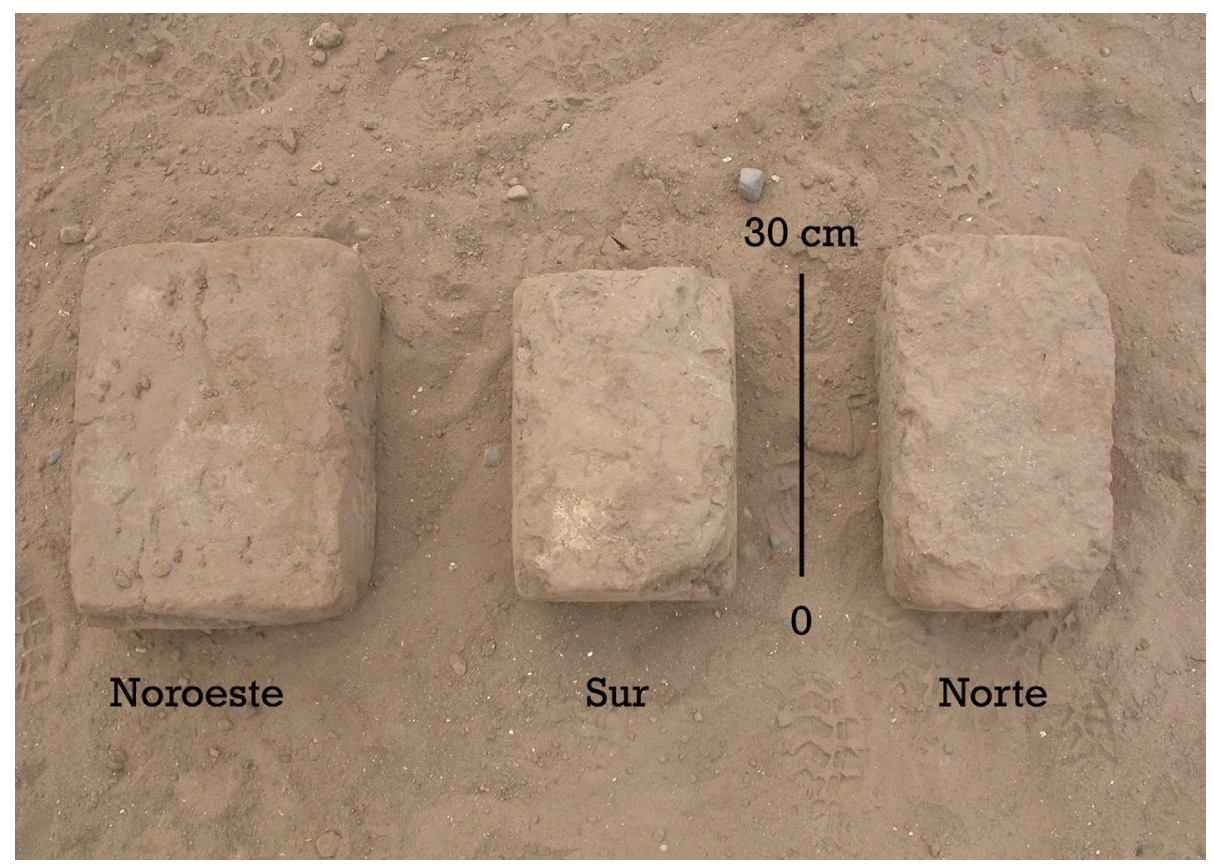

Figura 5. Adobes de tres localidades diferentes, noroeste, sur y norte, en la Unidad 16 de la Huaca de la Luna.

de adobes en Farfán, de los 4826 medidos, produjo los resultados encontrados en la Huaca de la Luna. Creo que este resultado es significante e indica un contraste entre los tipos de producción de adobe en ambos lugares.

Además, un análisis de los datos provistos por Moubarac (2002), recolectados de las Huacas de Moche, hizo que tuviera que revisar algunas de las suposiciones hechas por Cavallaro y Shimada (1988). Aunque ampliamente citado en la literatura arqueológica, el estudio de Hastings y Moseley (1975) no fue reexaminado estadísticamente hasta muchos años después por Moubarac (2002). La tesis de Moubarac es excepcional al presentar datos altamente necesarios sobre adobes individuales, incluyendo las marcas, las dimensiones y el tipo de suelo. Este es el tipo de información necesaria para poder evaluar el modelo de trabajo en adobes de Moseley. La muestra de adobes de Moubarac es de la Huaca de la Luna, la Huaca del Sol y la zona urbana entre ambas pirámides. Su muestra consta de 6893 adobes, aunque provee datos numéricos para solamente 293 ladrillos con marcas de fabricantes (ibíd., 116-122). De estos 293 ladrillos marcados, he escogido solamente aquellos con un número adecuado (más de cinco adobes) para cada marca de fabricantes para el re-análisis ( $\mathrm{n}=168)$.

Durante el trabajo de campo, me pude percatar que adobes de diversas partes dentro de la Unidad 16 son de diferentes tamaños. Por ejemplo, adobes en el lado sur de la Unidad 16 tendieron a ser más pequeños que los ladrillos 


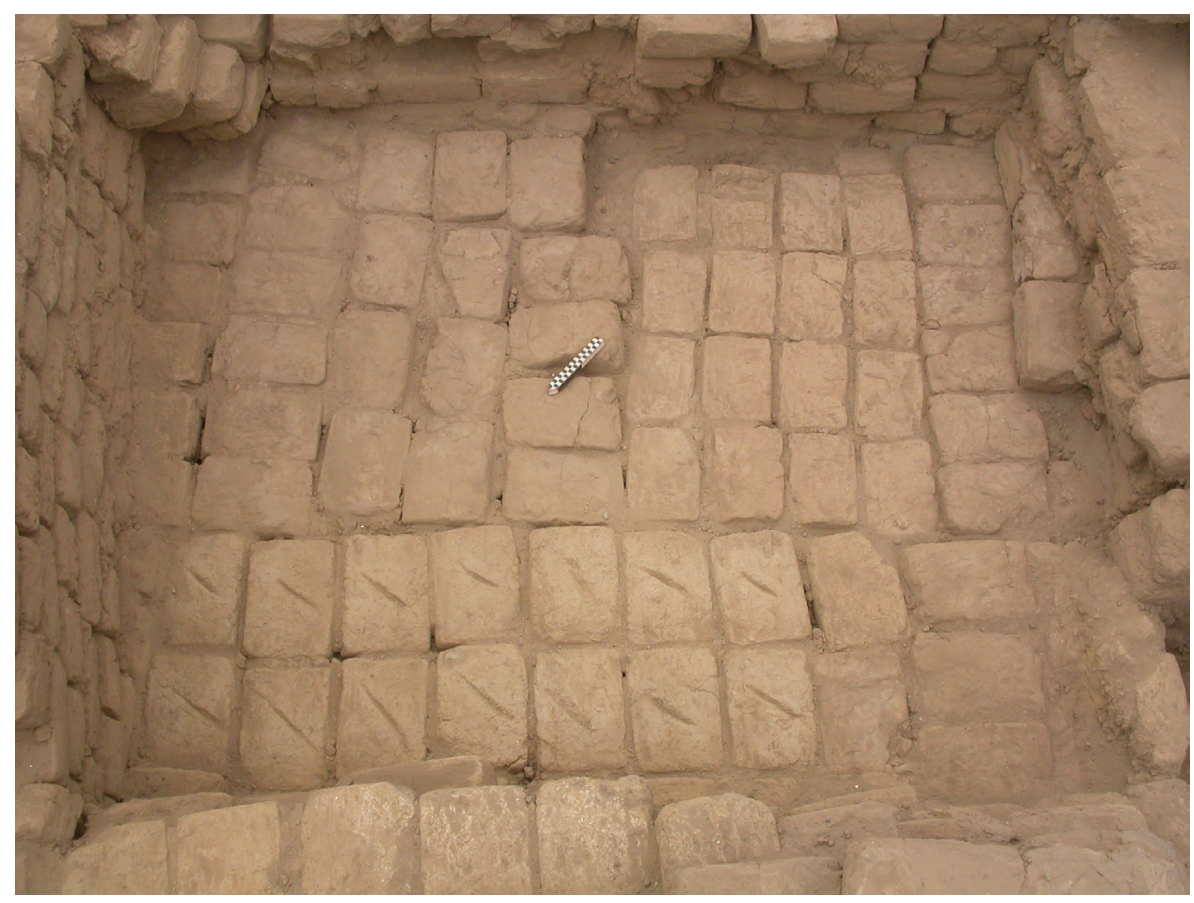

Figura 6. Grupo de adobes del mismo tamaño (31 por 22 por $13 \mathrm{~cm}$ ) y con la misma marca de fabricante en la Unidad 16, la Huaca de la Luna. La escala mide $20 \mathrm{~cm}$.

de la esquina noroeste (fig. 5). El diagrama de dispersión del largo y ancho corrobora mis observaciones (fig. 7). El análisis de los adobes por el algoritmo de agrupamiento, considerando el largo y ancho como variables (con tres grupos pre-determinados, el método de Ward), y el análisis en Chi-cuadrado de los grupos muestran que la diferencia de tamaño en los ladrillos de diferentes lugares es estadísticamente significativa (tablas 1 y 2). Este resultado demuestra que, algunas veces, adobes de diferentes tamaños caracterizan cada sección de las pirámides moche.

Tabla 1. Adobes de la Unidad 16, Huaca de la Luna.

\begin{tabular}{|c|c|c|c|c|c|c|c|}
\hline \multirow[b]{2}{*}{ Grupo } & \multirow[b]{2}{*}{$\mathrm{n}$} & \multicolumn{2}{|c|}{ Largo $(\mathrm{cm})$} & \multicolumn{2}{|c|}{ Ancho $(\mathrm{cm})$} & \multicolumn{2}{|c|}{ Alto $(\mathrm{cm})$} \\
\hline & & Promedio & $s$ & Promedio & $s$ & Promedio & $s$ \\
\hline 1 & 12 & 34.67 & 1.23 & 25.67 & 1.5 & 14.00 & 1.48 \\
\hline 2 & 24 & 28.04 & .91 & 19.75 & .68 & 9.67 & 1.46 \\
\hline 3 & 59 & 31.61 & 1.19 & 21.83 & .81 & 11.83 & 1.04 \\
\hline
\end{tabular}

De acuerdo con Moubarac (ibíd., 116-122), adobes del mismo tamaño podrían tener diferentes marcas de fabricantes. Esto indica que, muchas veces, diferentes talleres produjeron adobes del mismo tamaño. Esto es de esperarse. Si 


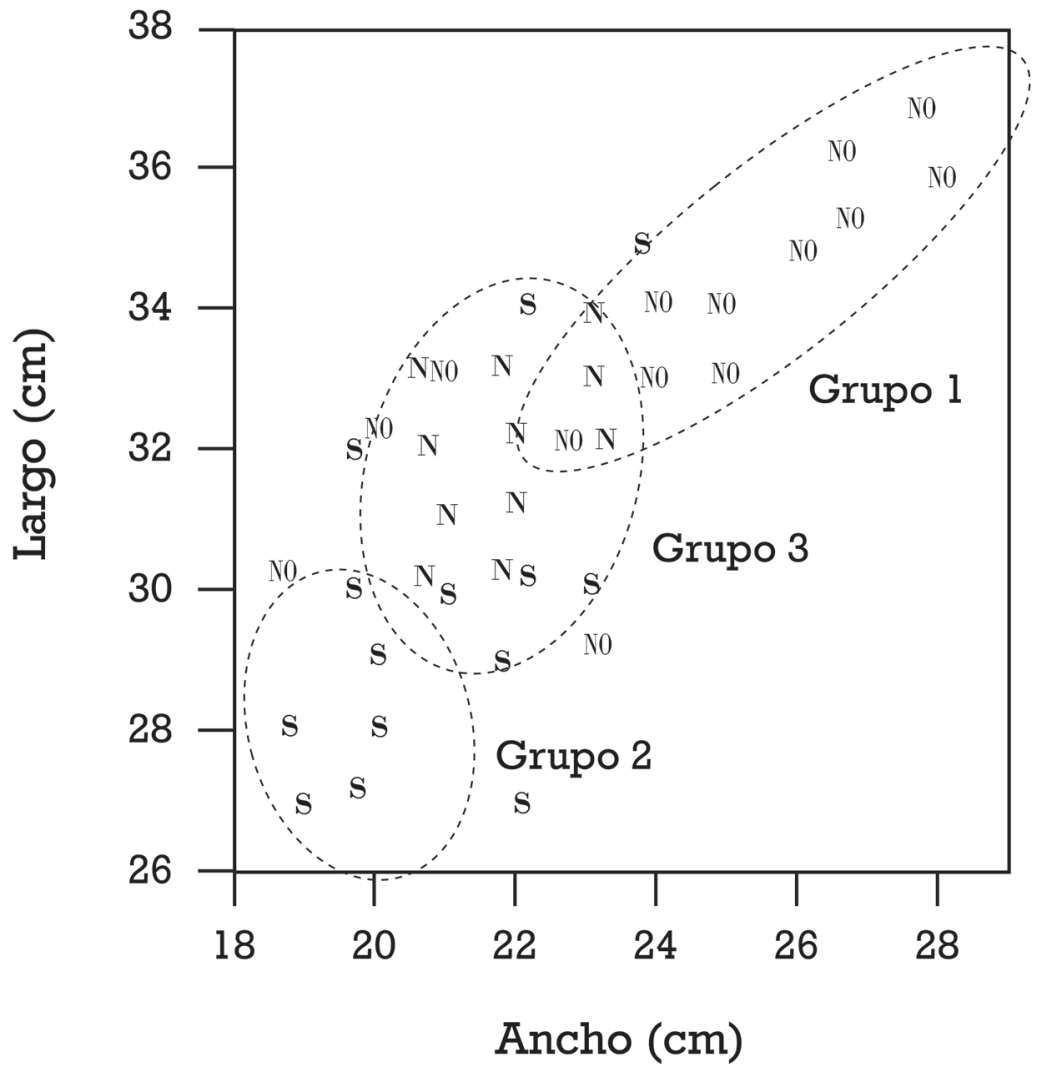

Figura 7. Diagrama de dispersión de los largos y anchos de los adobes tomados de la Unidad 16, Huaca de la Luna. "S" representa los adobes del lado sur de la Unidad 16; "N" denota los adobes del lado norte; y "NO" representa los adobes de la esquina noroeste. Las tres elipses con bordes entrecortados representan elipses de densidad $(p=.95)$ dibujadas alrededor de los grupos indicados en el análisis de grupo (cluster analysis).

la diferencia de tamaño distinguía a diferentes grupos de trabajo, entonces no había necesidad de grabar en ellos la marca de los fabricantes. Las marcas del fabricante se usaron porque muchas veces los talleres produjeron adobes de tamaños similares, y por eso, las marcas eran necesarias para evitar confusiones.

Moubarac (ibíd., 86-88) destaca que hay dos tamaños de adobes: estándar y grande. El histograma de los largos de los adobes demuestra dos picos, con un límite de separación de alrededor de 33-34 cm (fig. 8). Los adobes de tamaño estándar tienen un largo de menos de $33 \mathrm{~cm}$, y en promedio miden 30 por 19 por $13 \mathrm{~cm}$ (largo, ancho y alto). Los adobes grandes son más largos que $33 \mathrm{~cm}$ y en promedio miden 37 por 23 por $15 \mathrm{~cm}$ (tabla 3 ). Es posible que 


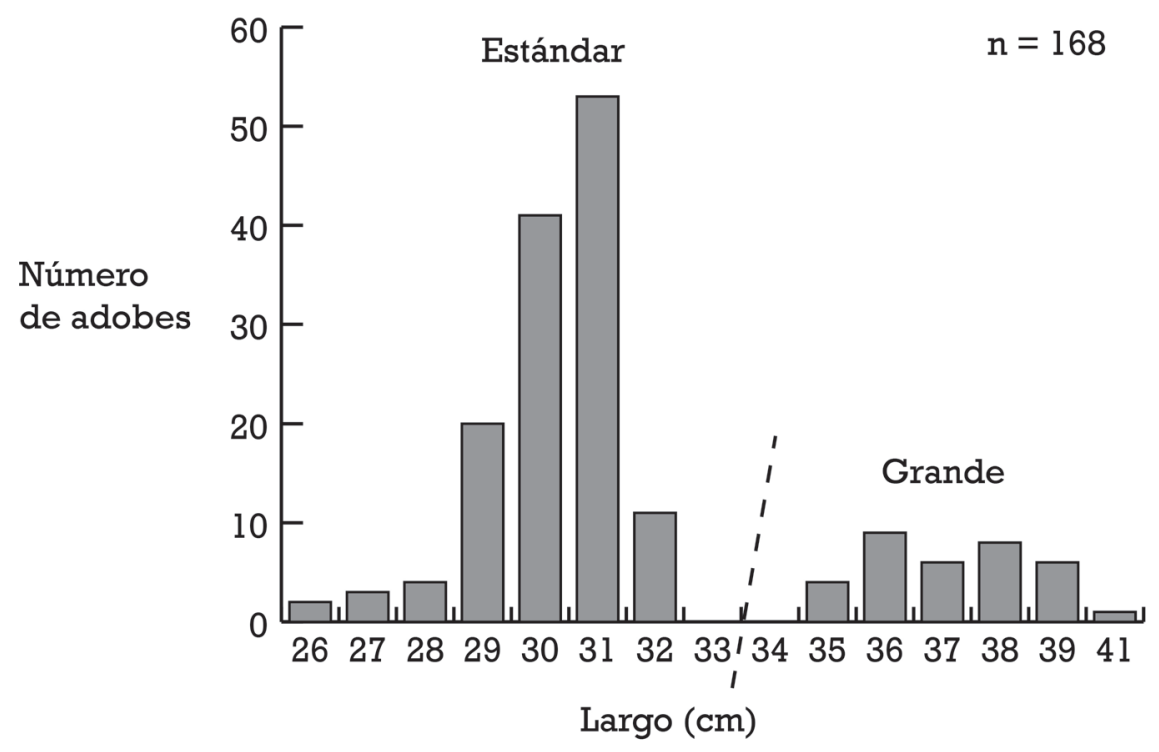

Figura 8. Histograma de los largos de los adobes de las Huacas de Moche (basado en los datos de Moubarac 2002, 116-122).

los adobes más grandes fueran usados en la base de la pared o edificación, un fenómeno observado en Chan Chan (Kolata 1982, 68). De hecho, una capa "gigante" de adobes, cada uno midiendo 96 por 60 por $21 \mathrm{~cm}$ y pesando algunos $200 \mathrm{~kg}$, fue encontrado $8 \mathrm{~m}$ debajo del Piso 1 de la Plaza 2 en la Huaca de la Luna (Tufinio 2003, 29).

Tabla 2. Adobes de la Unidad 16, Huaca de la Luna. Chi cuadrado es significativo $(p<.0001)$.

\begin{tabular}{lcccc}
\hline Localización & Grupo 1 & Grupo 2 & Grupo 3 & Total \\
\hline Norte & 0 & 0 & 47 & 47 \\
Noroeste & 11 & 1 & 4 & 16 \\
Sur & 1 & 23 & 8 & 32 \\
\hline
\end{tabular}

En algunos casos, tanto adobes de tamaño estándar como adobes grandes muestran la misma marca de fabricantes. Por ejemplo, marcas diagonales aparecen tanto en ladrillos de tamaño estándar como en adobes grandes, aunque algunas marcas, como barras verticales dobles, aparecen solamente en adobes de tamaño estándar (tabla 4). Adobes de tamaños diferentes con la misma marca de fabricantes también fueron encontrados en El Brujo (Franco, Gálvez y Vásquez 1994, 161). Esto significa que algunas comunidades o talleres produjeron tanto adobes grandes como adobes estándares. El hecho de que una comunidad fabricó adobes de diferentes tamaños no es sorprendente, porque, 
Tabla 3. Comparación de adobes estándares y grandes de la Huaca de la Luna (los datos son de Moubarac 2002, 116-122).

\begin{tabular}{|c|c|c|c|c|c|c|c|}
\hline \multirow[b]{2}{*}{ Tamaño } & \multirow[t]{2}{*}{$\mathrm{N}$} & \multicolumn{2}{|c|}{ Largo $(\mathrm{cm})$} & \multicolumn{2}{|c|}{ Ancho $(\mathrm{cm})$} & \multicolumn{2}{|c|}{ Alto $(\mathrm{cm})$} \\
\hline & & Promedio & $s$ & Promedio & $s$ & Promedio & $s$ \\
\hline Estándar & 134 & 30.22 & 1.18 & 19.00 & 1.04 & 13.38 & 1.16 \\
\hline Grande & 34 & 37.17 & 1.40 & 23.44 & 1.05 & 15.41 & 1.28 \\
\hline
\end{tabular}

Tabla 4. Adobes de las Huacas de Moche (los datos son de Moubarac 2002, 116-122).

\begin{tabular}{|c|c|c|c|c|c|c|c|}
\hline & Diagonal & $\begin{array}{l}\text { Doble barras } \\
\text { (al centro) }\end{array}$ & $\begin{array}{l}\text { Doble barras } \\
\text { (a un lado) }\end{array}$ & Punto & Semicírculo & $\begin{array}{l}\text { Líneas } \\
\text { verticales } \\
\text { (a un lado) }\end{array}$ & Dedo \\
\hline Estándar & 56 & 45 & 17 & 8 & 2 & 0 & 6 \\
\hline Grande & 13 & 0 & 0 & 5 & 8 & 8 & 0 \\
\hline Total & 69 & 45 & 17 & 13 & 10 & 8 & 6 \\
\hline
\end{tabular}

como ha señalado Moseley $(1975,192)$, estas marcas en los adobes abarcaron varias generaciones, y es también posible que, en un mismo taller, fabricantes de adobes con moldes diferentes estuvieran trabajando a la misma vez.

Hay más de dos tamaños de adobes. Incluso, en la categoría de adobes estándares, hay clases de menor tamaño o sub-tipos. Adobes de los lados norte y sur de la Unidad 16, representados por los Grupos 2 y 3 respectivamente, muestran una diferencia de unos pocos centímetros, observada en el trabajo de campo y confirmada a través de análisis estadístico. De haber agrupado todos los adobes de la Unidad 16 en un solo conjunto de datos, estas pequeñas diferencias no habrían sido percibidas y todos estos adobes hubieran sido clasificados como "estándares". Es por lo tanto necesario tomar en cuenta la posición en que están ubicados y separar los adobes de cada esquina de la unidad de excavación.

Ha sido argumentado que la construcción de segmentos separados se debe puramente a razones técnicas (y no a razones sociales o administrativas). Por ejemplo, Meneses y Chero $(1994,183)$ sugirieron que la construcción segmentada hizo que las estructuras fueran más resistentes a terremotos (contrario a Moseley 1975, 193). Si bien la separación de segmentos de la edificación puede ser atribuida al desarrollo de la tecnología de construcción, no hay una aparente razón técnica para el uso de adobes con marcas diferentes en secciones diferentes, y por lo tanto, una mejor explicación para el uso de marcas de fabricantes es que sirven para identificar grupos sociales. La división de proyectos de construcción basada en grupos sociales (ayllus o linajes) es una práctica común en los Andes, que ha sido documentada por etnohistoriadores (Thompson y Murra 1966, 636) y observada por etnógrafos tan recientemente como en los 1980s, por Urton (1988), en las alturas del pueblo Pacariqtambo, donde diferentes ayllus realizaron trabajos de mantenimiento del muro perimetral de 
la iglesia, cada ayllu siendo responsable de una sección determinada del muro.

Esto no significa que cada sección de las pirámides moche contiene adobes del mismo tamaño; siempre hay una mezcla, probablemente, debido a que los grupos de trabajo compartían materiales. Más aún, las sociedades andinas no tenían un solo sistema de organización laboral. De hecho, yo propondría lo contrario. El patrón moche para la marcación y construcción de adobes contrasta drásticamente con el de los chimú, y en la próxima sección, presento datos de Farfán para demostrar esta diferencia. Debido a que mi muestra de adobes de la Unidad 16 de la Huaca de la Luna es bastante limitada, futuros investigadores deben medir más adobes de la Huaca de la Luna y documentar su procedencia exacta para poder confirmar o refutar mis observaciones.

\section{FARFÁN Y LA CONQUISTA CHIMÚ DEL VALLE JEQUETEPEQUE}

Localizado en el valle Jequetepeque, Farfán fue excavado por primera vez por Richard Keatinge y Geoffrey Conrad (1983) en 1978 y luego por Carol Mackey $(2004,2006,2009)$ del 1999 al 2004. El lugar fue ocupado por tres Estados sucesivos: Lambayeque, Chimor o Chimú e Inca u Horizonte Tardío (tabla 5). Debido a su ubicación estratégica, en el cruce de dos rutas importantes (fig. 9), Farfán se convirtió en el centro administrativo del valle Jequetepeque bajo el Gobierno de los chimú y los incas (Mackey 2006, 328). Durante cada una de las ocupaciones, se construyeron nuevas estructuras, eventualmente creando los seis complejos de Farfán, que pueden ser vistos hoy día a lo largo de la carretera Panamericana (figs. 10 y 11, tabla 5). Por lo tanto, las investigaciones acerca de Farfán representan un caso de estudio importante sobre cómo la conquista imperial puede ser documentada usando la etnohistoria (Conrad 1990) y la arqueología (Mackey 2006, 2009).

El complejo más al norte de Farfán (Complejo VI) está a más de $3 \mathrm{~km}$ del complejo más al sur (Complejo I), a pesar de que su extensión de este a oeste es de solamente $0.25 \mathrm{~km}$. El Complejo II fue el primero construido por los chimú en Farfán. El mismo es identificado como chimú porque contiene elementos arquitectónicos similares a los encontrados en Chan Chan, la capital chimú

Tabla 5. Fechas, complejos asociados y formas de adobes de las tres ocupaciones de Farfán (véase Moore y Mackey 2008, fig. 39.3).

\begin{tabular}{|c|c|c|c|}
\hline Ocupación & Fecha (d. C.) & $\begin{array}{l}\text { Complejos } \\
\text { construidos }\end{array}$ & Forma de adobe \\
\hline Lambayeque & $1100-1310$ & III & Rectangular plano \\
\hline Chimú & $1310-1460$ & II, IV y VI & $\begin{array}{l}\text { Rectangular plano, algunos con superficie } \\
\text { superior abultada }\end{array}$ \\
\hline Inca & $1460-1532$ & Iy V & Rectangular plano, plano-convexo y óvalo \\
\hline
\end{tabular}




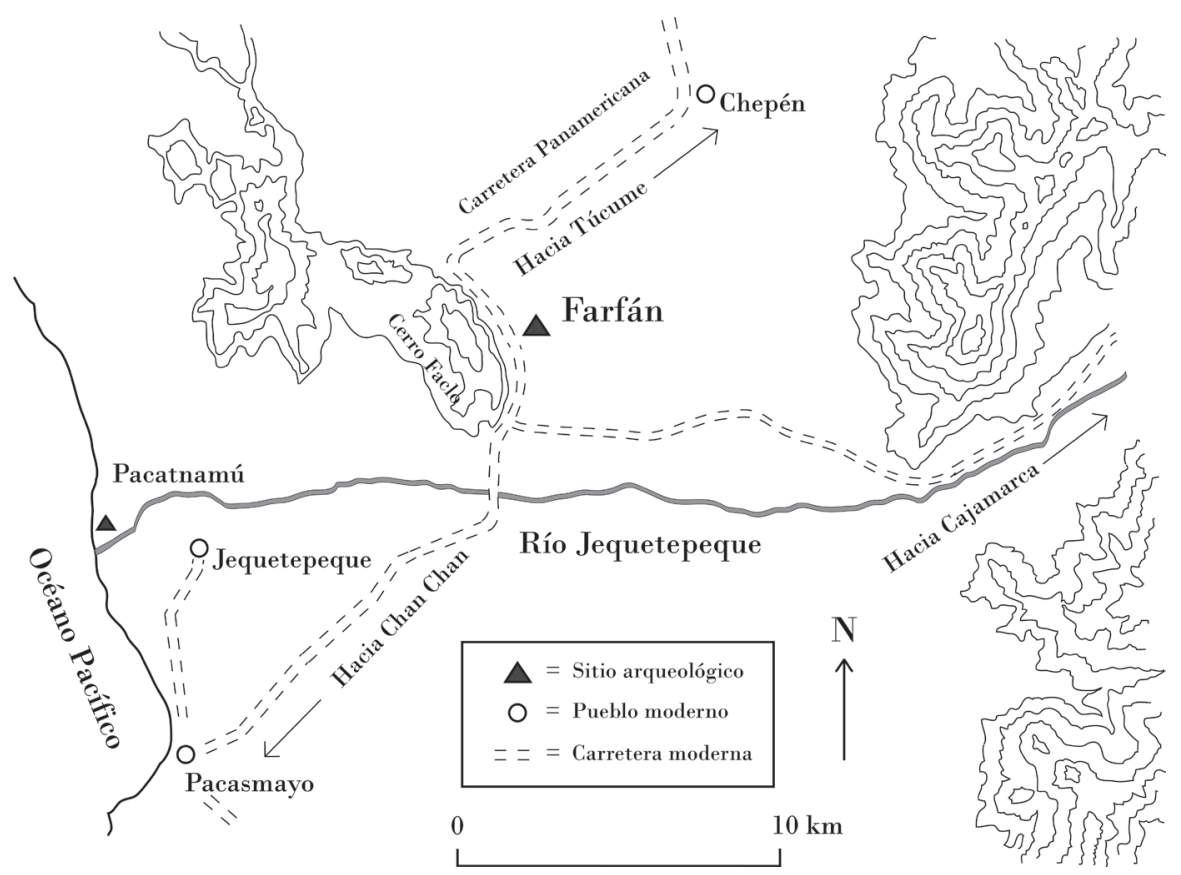

Figura 9. Mapa del valle Jequetepeque.

(Keatinge y Conrad 1983, 271). Por ejemplo, igual que en la Ciudadela Rivero en Chan Chan, la única entrada al Complejo II está al norte. Los visitantes se encuentran primero con una plaza, seguida de una serie de depósitos y audiencias, o recintos en forma de " $U$ " con nichos. Los depósitos o almacenes pudieron haber guardado objetos valiosos, y alguien sentado en la audiencia habría sido capaz de controlar el acceso a estos (Andrews 1974, 256), o, según John Topic (2003, 251-252), monitorizar el número de productos en los depósitos. Al lado sur del complejo está la plataforma funeraria (fig. 10), la cual da a otra serie de plazas y depósitos de almacenaje. Este arreglo espacial de plazas, depósitos, audiencias y plataforma funeraria en el Complejo II es análogo al plano arquitectónico de las ciudadelas de Chan Chan (Mackey 2009).

Keatinge y Conrad (1983) excavaron el Complejo II en Farfán para investigar la expansión chimú en el valle Jequetepeque. Basándose en el relato etnohistórico recopilado por Calancha (1977 [1638]), Keatinge (1982, 206-209) propuso que el Complejo II fue el palacio de Pacatnamú, un General chimú que conquistó el valle Jequetepeque durante la primera ola de la expansión chimú (Mackey 2009). Calancha (1977 [1638], 1228-1229) mencionó una cadena de cerros de un largo de tres leguas $(15 \mathrm{~km}$ ) cerca del palacio de Pacatnamú, y el cerro próximo a Farfán, Faclo, es de hecho aproximadamente $15 \mathrm{~km}$ de largo.

La importancia geográfica y económica del valle Jequetepeque pudo haber sido el motivo inicial para la conquista de la región (Conlee et al. 2004, 216); el valle estaba situado entre Chan Chan y los yacimientos de metales de Cajamarca (Lechtman 1976, 14), el Gobiermo de Sicán en el valle Lambayeque 


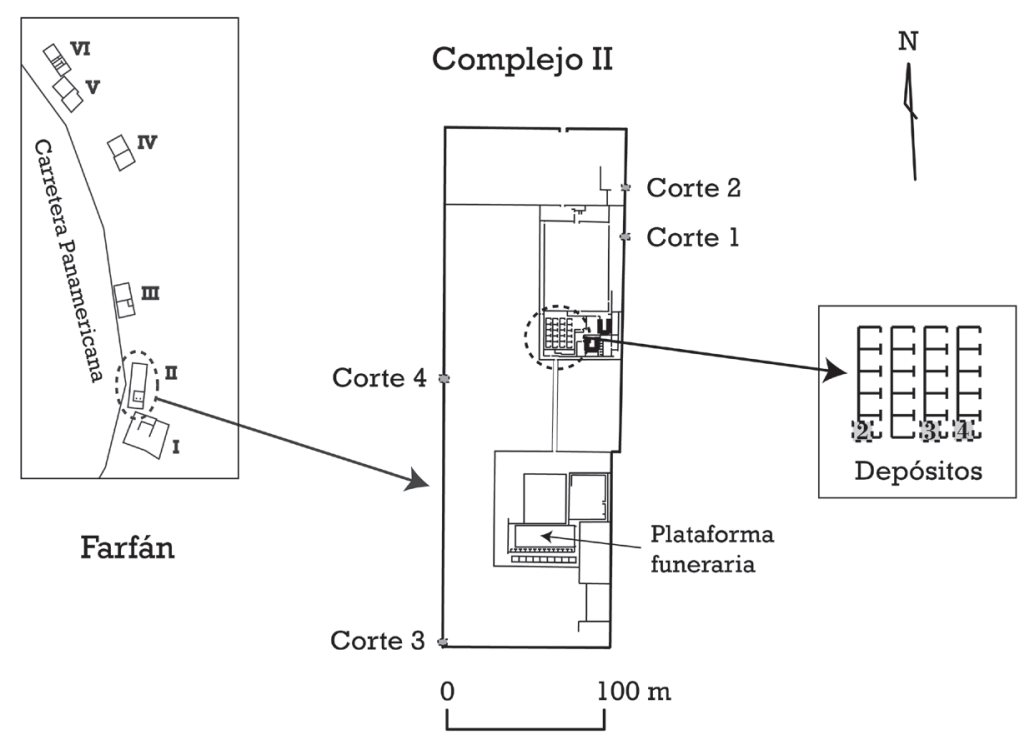

Figura 10. Complejo II, Farfán.

(Heyerdahl, Sandweiss y Narváez 1995; Tschauner 2001) y el preciado molusco Spondylus en Ecuador (Cordy-Collins 1990; Pillsbury 1996). Keatinge y Con$\operatorname{rad}(1983,282)$ postularon que, después de la conquista del valle Jequetepeque, los administradores chimú de Farfán manejaron el flujo de información y productos desde las regiones bajas del valle (por ejemplo, Talambo) hasta Chan Chan.

Entre 1999 y 2004 Mackey excavó todos los complejos de Farfán (Mackey y Jáuregui 2004). El trabajo de Mackey demostró que el Complejo III fue construido por el Gobierno local antes de la invasión chimú, y el Imperio inca lo siguió usando luego de conquistar la costa norte alrededor del año $1460 \mathrm{~d}$. C. (Mackey 2003). Localizado en la "intersección de imperios" (Kosok 1965, 118), Farfán albergó una mezcla heterogénea de personal administrativo local, chimú e inca, demostrando la importancia de la parte baja del valle Jequetepeque como centro administrativo.

\section{ESTRUCTURAS DE ADOBE EN FARFÁN}

Casi todas las estructuras en Farfán están hechas de adobe. Existen paredes hechas de tapia, pero son la minoría. Los complejos fueron hechos con adobes, y algunas de las paredes del perímetro, como las encontradas en el Complejo IV, aún alcanzan $4.5 \mathrm{~m}$ de altura (fig. 12). En la base, el ancho de las paredes del perímetro oscila entre 1.7 y $3 \mathrm{~m}$, con rocas grandes sirviendo como cimiento. Al- 


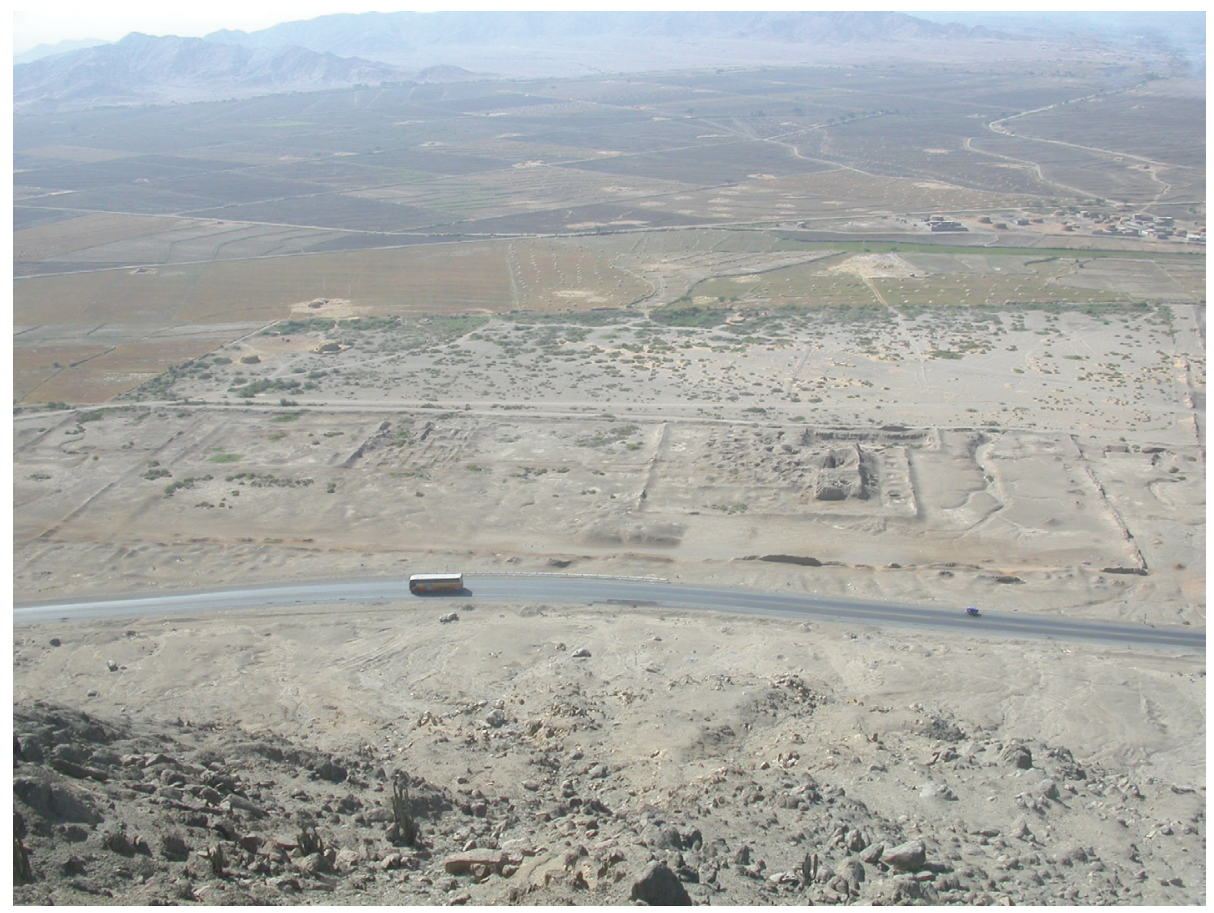

Figura 11. Complejo II, Farfán, vista desde el cerro Faclo. Un ómnibus en la carretera Panamericana sirve de escala.

gunas paredes del perímetro se vuelven más estrechas mientras van subiendo, quizás para garantizar su estabilidad. Algunas paredes dentro del complejo no son tan altas como las del perímetro. Estas no se vuelven estrechas en la parte superior, ni tampoco contienen grandes rocas en su base. En su lugar, una capa de gravilla sirve como cimiento para estas paredes al interior del complejo.

Los muros del complejo fueron hechos de adobe. En la construcción de los muros, los albañiles chimú colocaron capas de adobes pegados con mortero. Algunas veces, pedazos rotos de mortero o adobes fueron usados como relleno, una práctica observada en Chan Chan (Day 1982a, 340). Después de que todos los adobes y el mortero eran colocados, los albañiles aplicaban una capa de enlucido (alrededor de $3 \mathrm{~cm}$ de grosor) a cada lado de la pared. Los adobes fueron colocados usando la configuración de soga y tizón; es decir, los adobes de cada capa fueron colocados perpendicularmente a las capas debajo y encima de la misma. Una capa tendría adobes paralelos (longitudinalmente) a la pared, y la capa de encima tendría adobes perpendiculares a la pared, y así sucesivamente. Todas las paredes y estructuras en Farfán fueron construidas a soga y tizón.

La construcción en Farfán refleja tanto las tradiciones locales (valle Jequetepeque) como chimú (valle Moche) (tabla 6). Igual que las estructuras en Chan Chan, los muros de los perímetros de los complejos de Farfán fueron construidos casi completamente con adobes rectangulares y planos. Las estruc- 


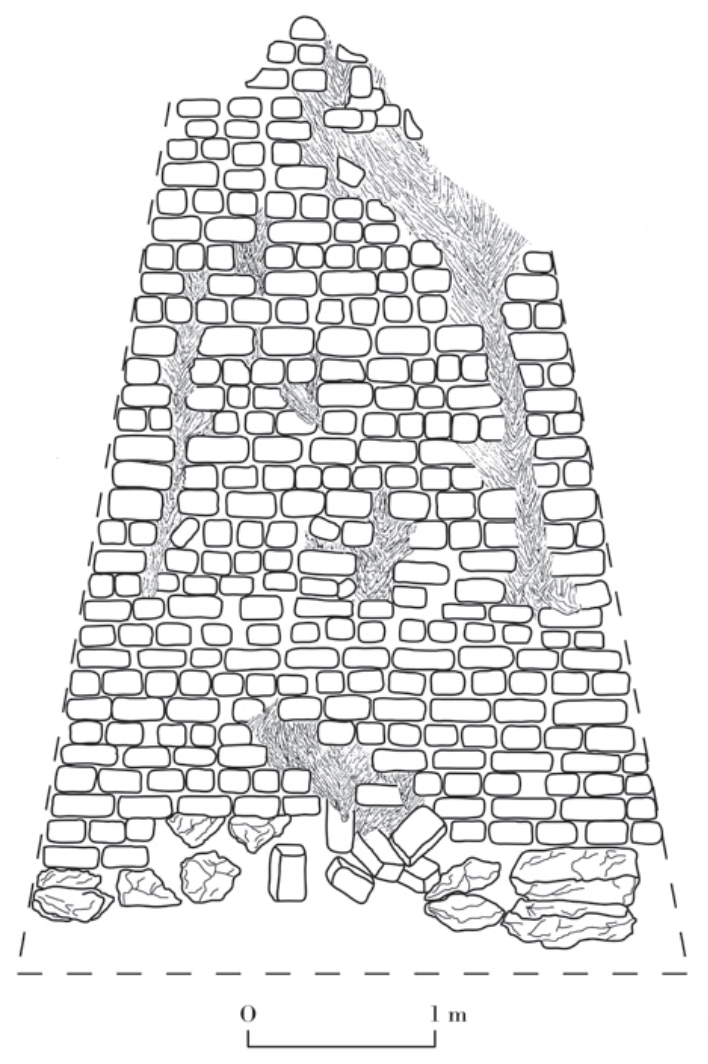

Figura 12. Corte transversal del muro norte del perímetro del Complejo IV, Farfán (diagrama basado en Mackey y Jáuregui 2001, fig. 8). Observe la configuración soga y tizón de los adobes, fundación de rocas y la pared estrechándose en el tope.

turas de Pacatnamú, un sitio del periodo Intermedio Tardío en el valle Jequetepeque, tienen tanto adobes rectangulares como adobes plano-convexos. Los adobes plano-convexos, con una superficie superior abultada, son comunes en estructuras del periodo Intermedio Tardío en los valles Lambayeque y La Leche. Algunas estructuras en Farfán, especialmente las que fueron modificadas o los anexos construidos durante el periodo Inca, contienen una mezcla de adobes rectangulares y plano-convexos.

Todas las paredes y estructuras de adobe (por ejemplo, las plataformas funerarias) en Farfán fueron hechas de adobes sólidos. En cambio, algunos muros en Chan Chan ejemplifican el método de cámaras rellenas (Day 1982b, 55-57). En Chan Chan, los adobes en las bases de los muros eran más grandes que los adobes del tope (Kolata 1982, 68), un fenómeno que no se encuentra en Pacatnamú (McClelland 1986, 41) o Farfán. Los adobes de Farfán, Chan Chan 
Tabla 6. Comparación de las técnicas constructivas en Chan Chan, Pacatnamú y Farfán.

\begin{tabular}{|c|c|c|c|}
\hline & Chan Chan & Pacatnamú & Farfán \\
\hline Forma de adobe & $\begin{array}{l}\text { La mayoría rectangu- } \\
\text { lar, pocos adobes } \\
\text { plano-convexos }\end{array}$ & $\begin{array}{l}\text { Una mezcla de rect- } \\
\text { angular y plano- } \\
\text { convexo }\end{array}$ & $\begin{array}{l}\text { La construcción } \\
\text { chimú hecha de } \\
\text { adobes rectangula- } \\
\text { res; modificaciones } \\
\text { y construccio- } \\
\text { nes posteriores } \\
\text { muestran una } \\
\text { mezcla de adobes } \\
\text { rectangulares y } \\
\text { plano-convexos }\end{array}$ \\
\hline Técnica constructiva & $\begin{array}{l}\text { Adobes sólidos y } \\
\text { cámaras rellenas }\end{array}$ & $\begin{array}{l}\text { Adobes sólidos, } \\
\text { algunas estruc- } \\
\text { turas de cámara } \\
\text { rellena }\end{array}$ & Adobes sólidos \\
\hline $\begin{array}{l}\text { Presencia de } \\
\text { segmentos }\end{array}$ & Sí & Sí & No observado \\
\hline $\begin{array}{l}\text { Adobes de mayor } \\
\text { tamaño encontrados } \\
\text { hacia la base del } \\
\text { muro }\end{array}$ & Sí & No & No \\
\hline Marcas de fabricantes & No & $\begin{array}{l}\text { No (solamente se } \\
\text { encontró en una } \\
\text { rampa) }\end{array}$ & No \\
\hline
\end{tabular}

(Kolata 1978, 163) y Pacatnamú (siendo la única excepción algunos adobes marcados de una rampa; véase McClelland 1986, 39) no tienen marcas de fabricantes. Sin embargo, se encuentran marcas de fabricantes en los adobes de Túcume, en el valle de La Leche, durante el periodo Intermedio Tardío (Sandweiss 1995, 164-166).

Los muros en Farfán no muestran la construcción en segmentos, una práctica encontrada en Chan Chan (Day 1982b, 57) y Pacatnamú (McClelland 1986, 41). La superficie expuesta de las paredes en los Complejos II y IV en Farfán, en las cuales el enlucido ha sido removido por la lluvia y el viento, revela la falta de segmentación.

Los adobes de Farfán son más parecidos a los de Pacatnamú (ibíd., fig. 4), un sitio arqueológico local en el valle Jequetepeque, que a los adobes de Chan Chan. Las ciudadelas construidas más tarde en Chan Chan fueron hechas usando adobes rectangulares altos, un tipo totalmente ausente en Farfán. El Complejo II de Farfán, así pues, copió el plano de estas posteriores ciudadelas de Chan Chan en el valle Moche, aunque sus adobes fueron manufacturados por fabricantes de adobes locales, en vez de fabricantes de adobes (usando sus propios moldes) de la capital imperial. Por lo tanto, este es un caso en el que vemos que los albañiles locales construyeron estructuras siguiendo el estilo de 
sus conquistadores, muy parecido a como los indígenas andinos construían iglesias siguiendo las reglas españolas durante el periodo colonial (Fraser 1990).

\section{ANÁLISIS DE LA VARIABILIDAD DE ADOBES EN FARFÁN}

Durante seis temporadas de trabajo de campo (1999-2004), 4826 adobes en Farfán fueron medidos (tabla 7). Miembros del Proyecto Arqueológico de Farfán documentaron el largo, ancho, alto, forma y ubicación de los adobes. Los adobes de Farfán tenían tres formas: rectangular, rectangular plano-convexo (adobes rectangulares con "topes redondeados" [Kroeber 1930, 58]) y ovalados plano-convexos (fig. 13). Los adobes rectangulares fueron hechos en moldes, mientras que los ladrillos ovalados plano-convexos fueron formados a mano (Shimada 1990, 352). Las construcciones del periodo Chimú consistían casi exclusivamente de adobes rectangulares, mientras que las estructuras subsiguientes del Horizonte Tardío incluían los tres tipos de adobes. Mi análisis solamente se concentrará en los adobes rectangulares encontrados en contextos chimú.

Tabla 7. Los promedios de largo, ancho y alto; proporción de largo y ancho, y proporción de alto y ancho de los adobes de los seis complejos de Farfán.

\begin{tabular}{lrccccc}
\hline Complejo & \multicolumn{1}{c}{$\mathrm{n}$} & Largo & Ancho & Alto & Largo/ancho & Alto/ancho \\
\hline I & 152 & 29.8 & 16.7 & 11.8 & 1.80 & 0.71 \\
II & 775 & 30.7 & 17.2 & 10.9 & 1.82 & 0.64 \\
III & 1695 & 30.2 & 17.4 & 11.4 & 1.75 & 0.67 \\
IV & 583 & 29.3 & 17.3 & 10.9 & 1.72 & 0.64 \\
V & 116 & 28.5 & 19.1 & 13.2 & 1.53 & 0.70 \\
VI & 1505 & 28.7 & 18.1 & 12.4 & 1.61 & 0.70 \\
\hline
\end{tabular}

Antes del 2003, todas las muestras de adobes provinieron de unidades excavadas con elementos arquitectónicos expuestos como paredes, pisos, bancos, entradas, etc. En el 2003 y el 2004 hice cuatro cortes en los muros perimetrales del Complejo II (fig. 10) y una en el Complejo I. En cada corte, la posición exacta de los adobes fue documentada, tomando en cuenta la capa, la fila y la orientación (soga vs. tizón).

Cambios en los adobes a través del tiempo

De acuerdo con Kolata $(1978,1982)$, los adobes rectangulares planos son asociados con las ciudadelas tempranas de Chan Chan, mientras que los adobes rectangulares altos son asociados con construcciones posteriores (Cavallaro 1991, 15-18). En otras palabras, las ciudadelas tempranas, como la ciudadela Tello y la ciudadela Uhle, contienen adobes con una proporción de alto y ancho menos que los encontrados en ciudadelas posteriores, como la ciudadela Gran Chimú y 

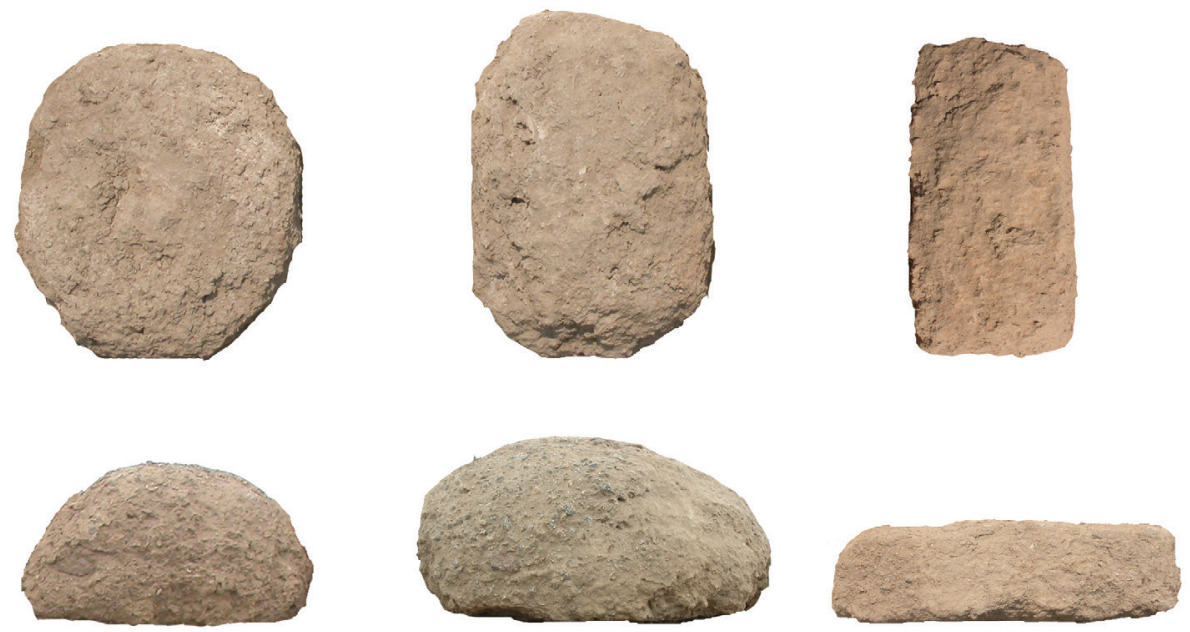

Figura 13. Tres tipos diferentes de adobes encontrados en Farfán. De izquierda a derecha: ovalado plano-convexo, plano-convexo y rectangular.

la ciudadela Laberinto. Ninguno de los adobes rectangulares de Farfán, incluso los construidos en periodos posteriores (periodo Inca), se acerca más a una proporción de alto y ancho parecida a la de los adobes de Chan Chan.

Tres proyectos diferentes han tomado muestras del Complejo II en Farfán: Kolata $(1978,190)$, Keatinge y Conrad $(1983,274)$ y el estudio presente. Los adobes que estudié en el Complejo II $(\mathrm{n}=775)$ tienen una proporción promedia de alto y ancho de 0.64 . La proporción promedia de alto y ancho encontrada por Keatinge y Conrad $(1983,274)$ en el Complejo II es 0.56 para las estructuras que incluyen las audiencias/depósitos $(\mathrm{n}=13)$ y 0.57 para la plataforma funeraria $(n=140)$. Las muestras de adobes de Kolata $(1978,190)$ en Farfán produjeron una proporción promedia de alto y ancho de 0.732 (tamaño de la muestra desconocido). Tello $(2004,33)$ también encontró unas dimensiones comunes para los ladrillos de Farfán $(29$ por 18 por $10 \mathrm{~cm}$, una proporción de alto y ancho de 0.55 ), aunque no especificó el tamaño de la muestra o dónde fueron medidos los adobes.

Estas diferencias en las medidas de los adobes de Farfán demuestran que distintas partes del Complejo II tienen adobes con dimensiones diferentes (tabla 8). Por ejemplo, los adobes del Corte $2(\mathrm{n}=108)$ tienen una proporción de alto y ancho de 0.78 , mientras que los adobes del Corte $4(\mathrm{n}=101)$ tienen una proporción de alto y ancho de 0.61 . De ahí que una muestra pequeña de adobes no sería suficiente para caracterizar la variabilidad de los adobes en un mismo complejo o sitio. 
Tabla 8. Adobes del Complejo II, Farfán.

\begin{tabular}{|c|c|c|c|c|c|c|c|}
\hline \multirow[b]{2}{*}{ Localización } & \multirow[b]{2}{*}{$n$} & \multicolumn{2}{|c|}{ Largo $(\mathrm{cm})$} & \multicolumn{2}{|c|}{ Ancho (cm) } & \multicolumn{2}{|c|}{ Alto $(\mathrm{cm})$} \\
\hline & & Promedio & $s$ & Promedio & $s$ & Promedio & $s$ \\
\hline Depósito 2 & 48 & 29.79 & 2.72 & 16.98 & 2.02 & 11.42 & 1.46 \\
\hline Depósito 3 & 52 & 30.06 & 1.78 & 17.81 & 1.66 & 10.79 & 1.45 \\
\hline Depósito 4 & 83 & 31.28 & 2.39 & 17.52 & 1.91 & 12.16 & 1.26 \\
\hline Corte 1 & 110 & 31.73 & 3.25 & 16.63 & 2.40 & 11.15 & 1.45 \\
\hline Corte 2 & 108 & 30.06 & 1.81 & 14.14 & 1.99 & 9.57 & 1.06 \\
\hline Corte 3 & 131 & 29.47 & 1.57 & 17.70 & 1.22 & 10.31 & 1.01 \\
\hline Corte 4 & 101 & 32.51 & 2.47 & 18.15 & 1.79 & 10.95 & 1.49 \\
\hline
\end{tabular}

En Farfán, una característica distintiva de construcciones posteriores es la presencia de adobes plano-convexos. Con la excepción de algunos adobes levemente plano-convexos $(n=3)$ encontrados en el Corte 1, todos los adobes chimú en Farfán eran rectangulares. Los adobes plano-convexos aparecen en los anexos y renovaciones realizadas durante el periodo del Horizonte Tardío o el Horizonte Chimú-Inca. Por ejemplo, una estructura al norte del Complejo II, la Residencia Elite C (no aparece en la fig. 10) fue construida completamente con adobes ovalados plano-convexos.

Diferencias sincrónicas en la dimensión de los adobes

Para probar las diferencias sincrónicas del tamaño de los adobes, se debe aislar el área en la cual las estructuras fueron construidas durante el mismo periodo. Una vez se establece la contemporaneidad cronológica, el análisis de la variabilidad de los adobes se puede realizar en varios niveles - comparando diferentes capas de adobes en un mismo corte de muestreo, comparando diferentes cortes de muestreo en una misma pared, comparando diferentes cortes de muestreo dentro un mismo complejo, comparando diferentes complejos en un mismo sitio, etc.

Para investigar las diferencias sincrónicas en las dimensiones de los adobes, coloqué cuatro cortes de muestreo de adobe en los muros perimetrales del Complejo II (fig. 10, tabla 8). Los muros perimetrales de Chan Chan impedían a las personas de afuera mirar al interior de los complejos rectangulares (Moore 1996, 117-118); así que, presumiblemente, los muros perimetrales de Farfán tuvieron que ser construidos antes de que el complejo pudiera funcionar apropiadamente. Los muros perimetrales fueron probablemente construidos en un tiempo relativamente corto, algunos meses o años, pero no durante décadas o siglos. Es poco probable que alguno de los administradores (quizás el General Pacatnamú) tuviera que esperar muchos años para poder usar el complejo. Además, debido a que no se encontraron segmentos separados en los muros de Farfán, estudié los adobes de diferentes depósitos para probar si cada depósito fue construido por un grupo distinto de trabajadores. 


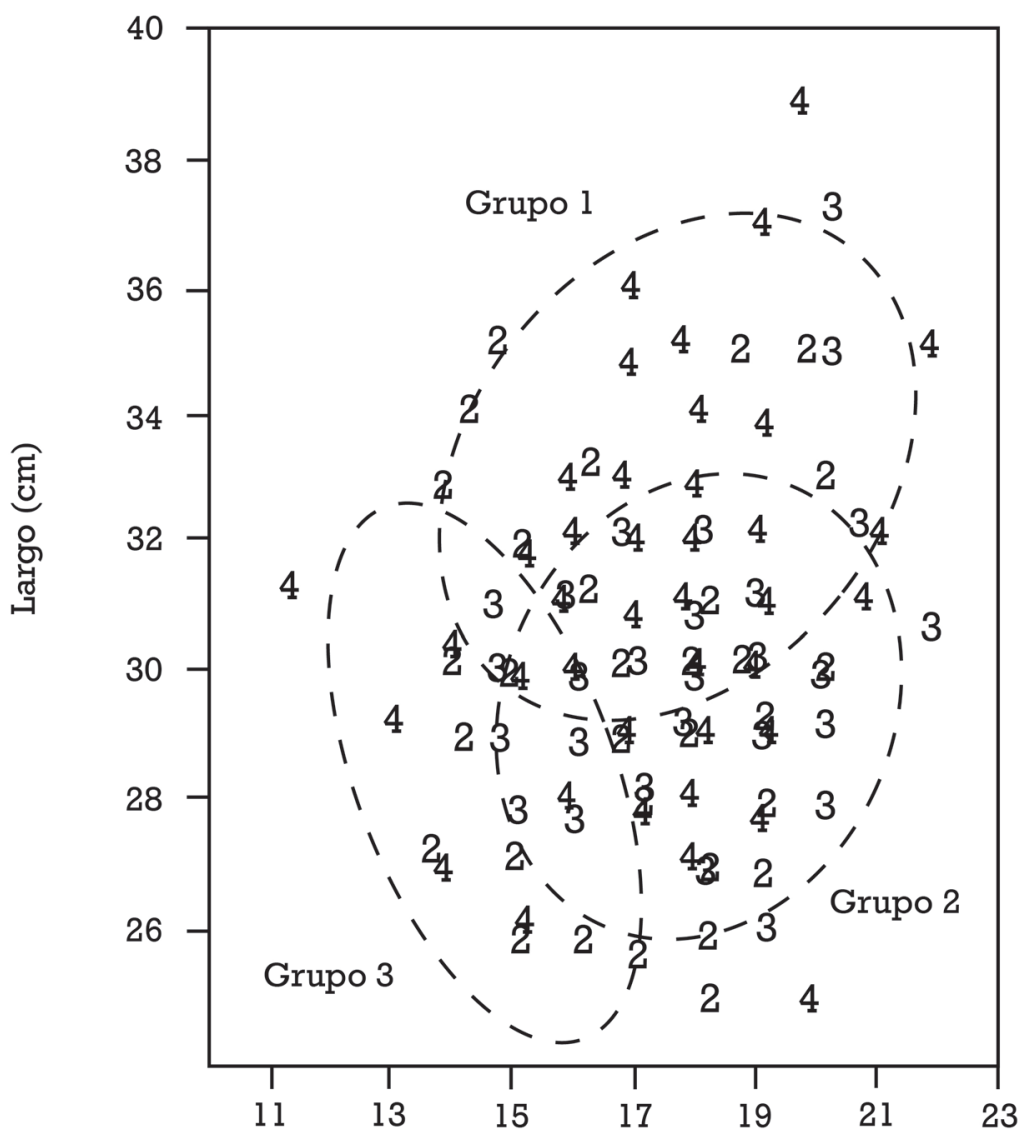

Ancho (cm)

Figura 14. Diagrama de dispersión de los largos y anchos de la muestra de adobes de los depósitos del Complejo II, Farfán. El número 2 representa adobes del Depósito 2; 3 representa adobes del Depósito 3; y 4 representa adobes del Depósito 4. Las elipses con líneas entrecortadas representan elipses de densidad $(p=.95)$ dibujadas alrededor de los grupos indicados en el análisis de grupo (cluster analysis). Compare con la fig. 7.

Mientras medía los adobes de Farfán, mi primera impresión fue que un área del sitio no tenía adobes más grandes o más pequeños que los adobes de cualquier otra área. Un diagrama de dispersión de los adobes estudiados de tres depósitos diferentes parecía confirmar mi observación (fig. 14). Sin embargo, el análisis de grupo (cluster analysis) de estos adobes (considerando el largo y ancho como variables, solución de tres grupos, método de Ward) demuestra que las diferencias entre los depósitos son estadísticamente significativas (tabla 
9). En otras palabras, la diferencia es muy sutil y no obvia a la vista. Dichas pequeñas diferencias también existen entre las partes del muro perimetral. Por ejemplo, adobes del Corte 2 son generalmente más angostos que otros adobes del Complejo II (tabla 8), mientras que los adobes del Corte 4 tienden a ser más largos.

Tabla 9. Adobes de los depósitos del Complejo II, Farfán. El análisis de grupo (cluster analysis) de estos adobes, considerando el largo y ancho como variables (solución de tres grupos, método de Ward), y el análisis de chi cuadrado de los grupos demuestran que la diferencia de tamaño entre adobes de diferentes lugares es estadísticamente significativa $(p<.0001)$.

\begin{tabular}{lcccc}
\hline Depósito & Grupo 1 & Grupo 2 & Grupo 3 & Total \\
\hline 2 & 12 & 23 & 13 & 48 \\
3 & 7 & 39 & 6 & 52 \\
4 & 41 & 33 & 9 & 83 \\
\hline
\end{tabular}

Aunque la diferencia en el tamaño de los adobes de los cortes es minúscula, es también estadísticamente significativa. La prueba de la media (Siegel 1956, 111-116), que compara el largo, ancho y alto de los adobes de diferentes cortes de muestreo, revela que hay menos de 0.1 por ciento de probabilidad de que los adobes procedían de la misma población (prueba unidireccional, Chicuadrado $=45.6776 ; d f=2, \mathrm{p}<.0001)$. En otras palabras, es poco probable que todos los adobes del Complejo II provinieran del mismo fabricante. Esto sugiere que múltiples fabricantes de adobes estuvieron envueltos en la construcción del Complejo II, y que un área de la construcción (un depósito o una sección de un muro) puede contener más adobes hechos por, supongamos, el Fabricante A que el Fabricante B. La diferencia entre los adobes de diversos cortes de muestreo no es obvia a la vista. Hay demasiada coincidencia en las dimensiones de los adobes como para distinguir los que son de diferentes cortes de muestreo (figs. 14 y 15). No se puede decir con total certeza, tomando sólo en cuenta su tamaño, dónde fue utilizado un adobe. Adobes rectangulares del Complejo IV, que data del periodo de la ocupación Chimú (Mackey 2009, 330), tienden todos a medir (más o menos) 30 por 17 por $11 \mathrm{~cm}$ (fig. 16). Así, el tamaño o las dimensiones de un adobe no son útiles para determinar el lugar en el que sería colocado en el complejo. Tanto el Fabricante A como el Fabricante B proveyeron adobes para la construcción del Depósito 2, pero no podemos separar los dos tipos de adobes fabricados por cada uno después de ser juntados y mezclados durante el proceso de la construcción.

Una de las secciones del muro norte del Complejo IV tenía capas alternas de adobes hechos de diversos tipos de suelos (fig. 17). Algunas capas incluían cantidades mayores de gravillas que las capas de encima y debajo. Capas alternas de adobes con diferentes marcas de fabricantes fueron encontradas en Galindo, un sitio moche (Lockard 2008, 287-289); estos patrones sugieren que 

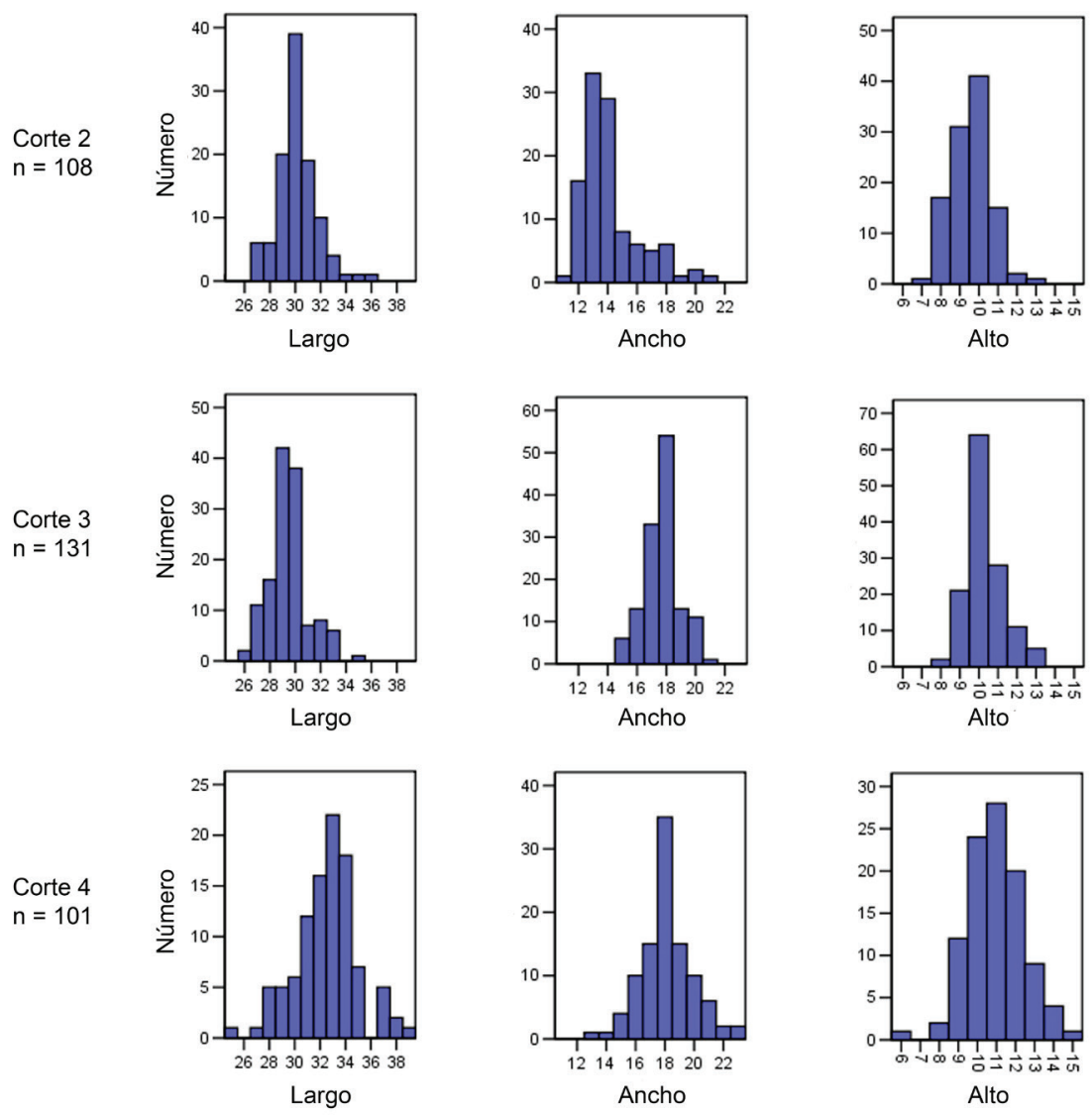

Figura 15. Histograma comparando el largo, ancho y altura (en centímetros) de los adobes de la muestra del Complejo II, Farfán.

ciertas secciones de una pared o una edificación fueron construidas en tramos horizontales con adobes obtenidos de diversas fuentes o talleres. En Farfán, los adobes encontrados en el mismo corte algunas veces tienen dimensiones diferentes (figs. 18-21 y tabla 10). Esto demuestra que adobes hechos en diferentes moldes (y por lo tanto, por diferentes fabricantes de adobes) fueron colocados en la misma área de la pared.

\section{Discusión}

Mis datos demuestran varias diferencias importantes en la producción y construcción de adobes entre la Huaca de la Luna y Farfán. Para entender estas di- 


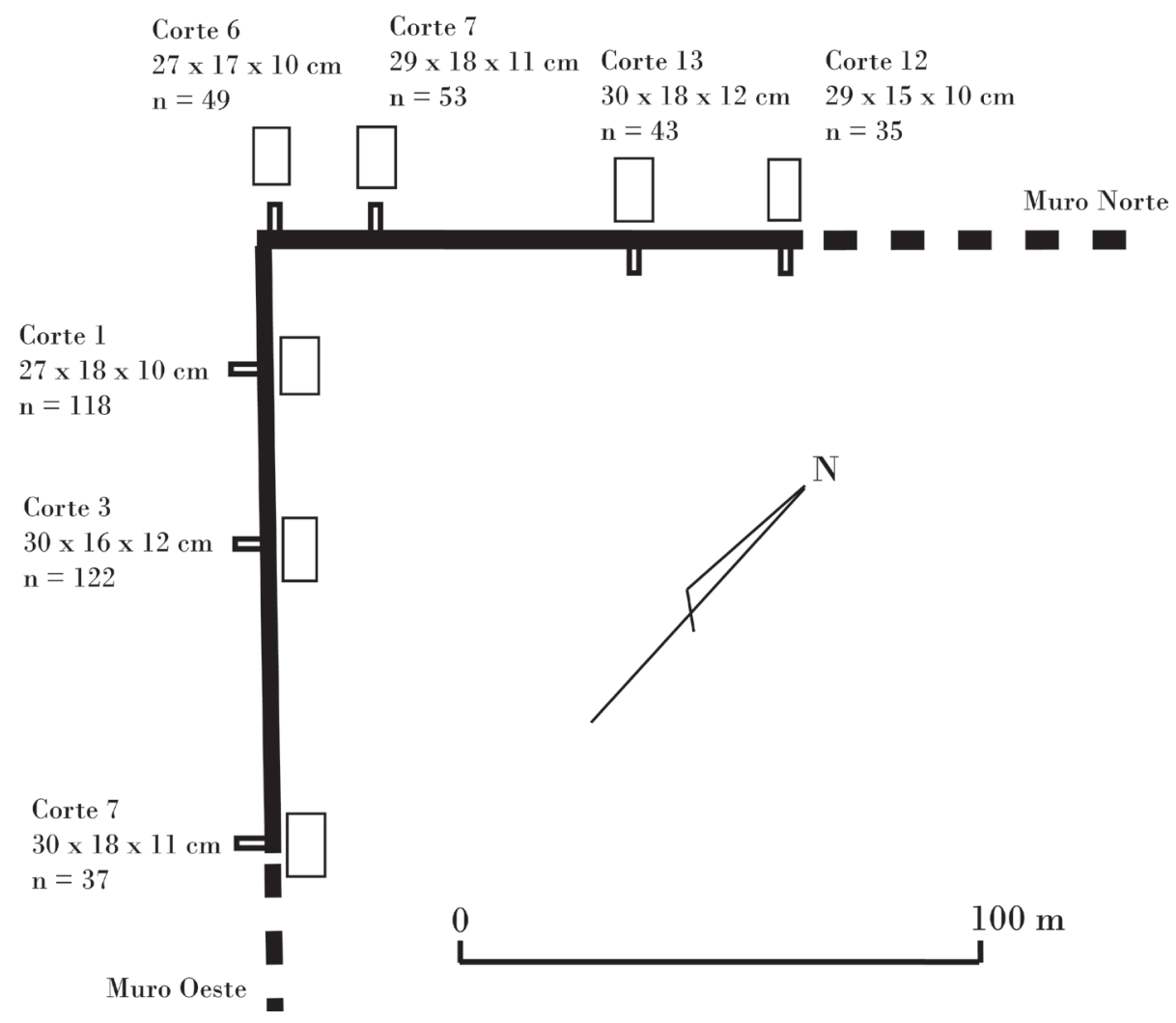

Figura 16. Esquina noroeste del Complejo IV de Farfán, mostrando los lugares de las unidades excavadas y el tamaño promedio de largo, ancho $y$ alto de los adobes encontrados en las unidades.

ferencias, sugiero que en la Huaca de la Luna, los fabricantes de adobes moche secaban sus adobes en áreas separadas (fig. 22, o Modelo A en la fig. 3). Cada grupo de trabajadores moche construyó las pirámides usando los respectivos conjuntos de adobes que produjeron. Hubo algún intercambio de adobes entre los diferentes grupos de trabajo, pero ese intercambio fue mínimo. Como resultado, los arqueólogos todavía pueden identificar diferentes grupos de adobes con específicas marcas de fabricantes o tamaños en la Huaca de la Luna. Mis datos corroboran observaciones previas hechas por Hastings y Moseley $(1975,202-203)$. 
Tabla 10. Medidas de adobes de las Capas 5 a 8 del Corte 3 del Complejo II, Farfán.

\begin{tabular}{|c|c|c|c|c|c|}
\hline Número & Capa & Largo $(\mathrm{cm})$ & Ancho (cm) & Alto $(\mathrm{cm})$ & Disposición \\
\hline 1 & 5 & 29 & 18 & 13 & Soga \\
\hline 2 & 5 & 29 & 16 & 13 & Soga \\
\hline 3 & 5 & 29 & 16 & 11 & Soga \\
\hline 4 & 5 & 27 & 18 & 10 & Soga \\
\hline 5 & 5 & 29 & 16 & 12 & Soga \\
\hline 6 & 5 & 28 & 18 & 9 & Soga \\
\hline 7 & 5 & 31 & 19 & 10 & Soga \\
\hline 8 & 5 & 28 & 18 & 11 & Soga \\
\hline 9 & 5 & 29 & 16 & 12 & Soga \\
\hline 10 & 5 & 28 & 18 & 9 & Soga \\
\hline 11 & 5 & 28 & 19 & 10 & Soga \\
\hline 12 & 5 & 27 & 18 & 9 & Soga \\
\hline 13 & 5 & 29 & 18 & 9 & Soga \\
\hline 14 & 5 & 29 & 17 & 10 & Soga \\
\hline 15 & 5 & 30 & 16 & 10 & Tizón \\
\hline 16 & 5 & 27 & 18 & 9 & Soga \\
\hline 17 & 5 & 28 & 18 & 10 & Soga \\
\hline 18 & 6 & 27 & 18 & 10 & Tizón \\
\hline 19 & 6 & 29 & 18 & 10 & Tizón \\
\hline 20 & 6 & 27 & 17 & 9 & Tizón \\
\hline 21 & 6 & 28 & 15 & 12 & Tizón \\
\hline 22 & 6 & 30 & 18 & 11 & Tizón \\
\hline 23 & 6 & 27 & 17 & 10 & Tizón \\
\hline 24 & 6 & 32 & 15 & 10 & Tizón \\
\hline 25 & 6 & 28 & 17 & 10 & Tizón \\
\hline 26 & 6 & 28 & 18 & 10 & Tizón \\
\hline 27 & 6 & 33 & 20 & 11 & Tizón \\
\hline 28 & 6 & 31 & 17 & 10 & Tizón \\
\hline 29 & 6 & 30 & 17 & 10 & Tizón \\
\hline 30 & 6 & 28 & 17 & 9 & Tizón \\
\hline 31 & 6 & 30 & 19 & 10 & Tizón \\
\hline 32 & 6 & 32 & 17 & 9 & Tizón \\
\hline 33 & 6 & 29 & 19 & 10 & Tizón \\
\hline 34 & 6 & 29 & 18 & 11 & Tizón \\
\hline 35 & 6 & 33 & 20 & 12 & Tizón \\
\hline 36 & 7 & 30 & 20 & 10 & Soga \\
\hline 37 & 7 & 30 & 19 & 9 & Soga \\
\hline 38 & 7 & 29 & 18 & 11 & Soga \\
\hline 39 & 7 & 27 & 19 & 10 & Soga \\
\hline 40 & 7 & 30 & 16 & 10 & Soga \\
\hline 41 & 7 & 29 & 17 & 8 & Soga \\
\hline 42 & 7 & 30 & 18 & 10 & Soga \\
\hline 43 & 7 & 29 & 18 & 10 & Soga \\
\hline 44 & 7 & 29 & 17 & 11 & Soga \\
\hline
\end{tabular}




\begin{tabular}{llllrl}
45 & 7 & 29 & 18 & 10 & Soga \\
46 & 7 & 29 & 17 & 10 & Soga \\
47 & 7 & 30 & 18 & 10 & Soga \\
48 & 7 & 30 & 18 & 10 & Soga \\
49 & 7 & 29 & 17 & 10 & Soga \\
50 & 7 & 30 & 18 & 9 & Soga \\
51 & 7 & 29 & 20 & 10 & Soga \\
52 & 7 & 29 & 17 & 11 & Soga \\
53 & 7 & 35 & 17 & 12 & Soga \\
54 & 7 & 29 & 16 & 11 & Soga \\
55 & 8 & 30 & 18 & 10 & Tizón \\
56 & 8 & 32 & 18 & 10 & Tizón \\
57 & 8 & 28 & 18 & 10 & Tizón \\
58 & 8 & 27 & 18 & 9 & Tizón \\
59 & 8 & 28 & 19 & 10 & Tizón \\
60 & 8 & 27 & 19 & 9 & Tizón \\
61 & 8 & 26 & 18 & 9 & Tizón \\
62 & 8 & 33 & 16 & 11 & Tizón \\
63 & 8 & 33 & 15 & 9 & Tizón \\
64 & 8 & 33 & 15 & 9 & Tizón \\
65 & 8 & 29 & 15 & 11 & Soga \\
66 & 8 & 26 & 17 & 8 & Tizón \\
67 & 8 & 29 & 18 & 10 & Tizón \\
\hline
\end{tabular}

Por el contrario, los fabricantes de adobes en Farfán ponían sus adobes juntos a secar, y luego otro grupo de trabajadores, distinto a los fabricantes, tomaban los adobes indiscriminadamente para construir las paredes del complejo. Por consiguiente, los arqueólogos han encontrado una mezcla de adobes de diversos tamaños en un mismo segmento de construcción (fig. 22 o Modelo B en la fig. 3). Debido a que los adobes de diversos fabricantes se juntaban y mezclaban en un mismo grupo, la diferencia en el tamaño de los adobes en los muros o los depósitos en Farfán no es tan fuerte como la diferencia en el tamaño de los adobes en la Huaca de la Luna (compare la fig. 7 con la fig. 14).

¿Por qué los albañiles moche usaron columnas separadas de adobes para distinguir una parte del monumento de la otra, mientras que los albañiles chimú no? Una posible explicación es que los complejos rectangulares chimú en Farfán, a diferencia de las construcciones en la Huaca de la Luna o la Huaca del Sol, pueden ser divididos en subunidades claras. Por ejemplo, se le podría asignar a un grupo de trabajadores terminar todos los depósitos, mientras otro grupo de trabajadores podrían ser responsables de construir el muro perímetral. De hecho, Day (1982a, 340) sugirió que en Chan Chan "paredes más pequeñas de las estructuras dentro de las ciudadelas usualmente no tienen juntas 


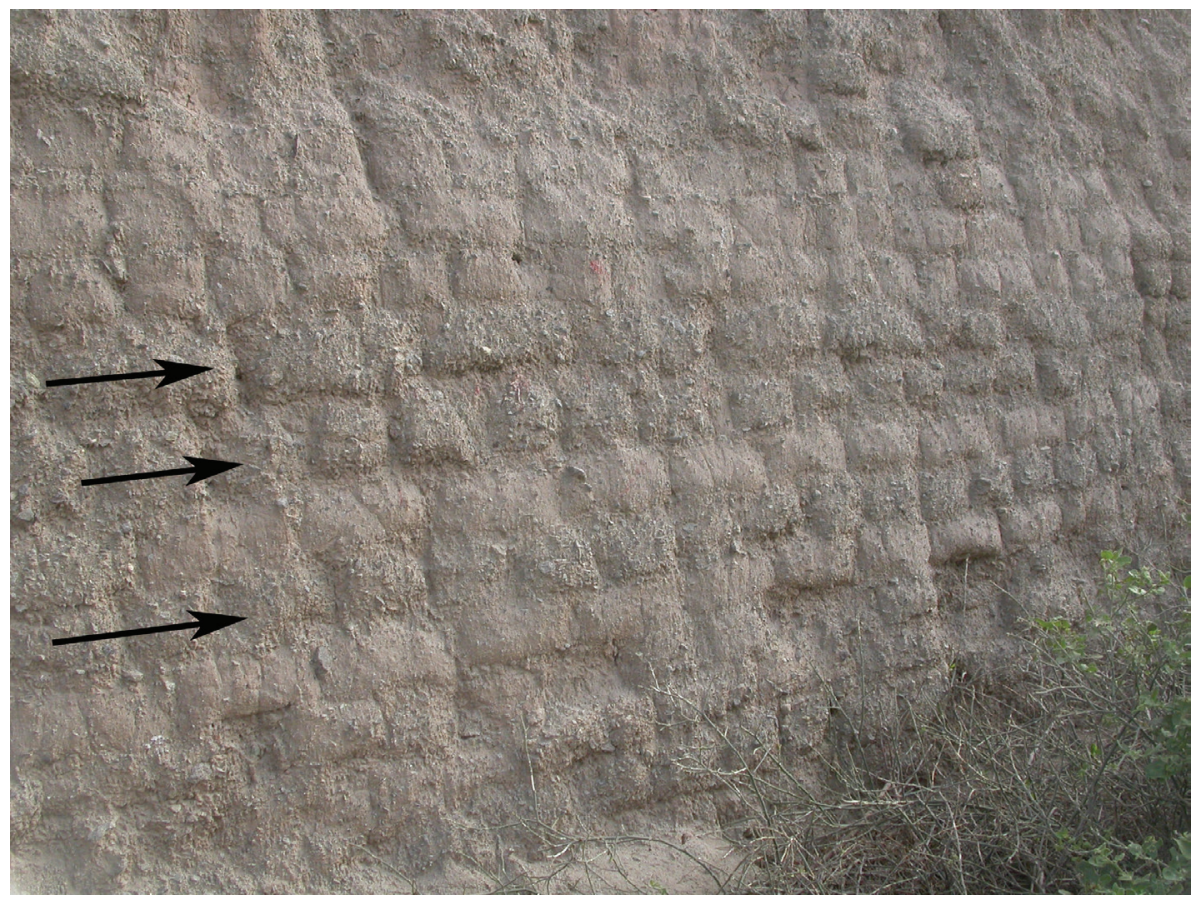

Figura 17. Una sección del muro norte del Complejo IV, Farfán. Observe las capas de adobes (indicadas por las flechas) con más inclusiones de gravillas que las capas adyacentes.

o secciones, pero el volumen de estas paredes es mucho menor que el volumen de las paredes grandes circundantes [las cuales estaban divididas en segmentos]. Quizás, paredes pequeñas completas representan grupos de trabajo, equivalentes a una sección o a secciones de un muro más grande".

En cambio, monumentos como la Huaca del Sol y la Huaca de la Luna requirieron "divisiones" para diferenciar un segmento del otro. Debido a que las pirámides moche están mayormente hechas de bloques sólidos de adobes, sería muy difícil para los supervisores saber dónde un grupo específico de trabajadores habían comenzado a construir y dónde otro había acabado sin ningún tipo de segmentación. Por lo tanto, segmentos separados podían ayudar a distinguir una tarea específica de las demás.

Para poder explicar por qué los fabricantes de adobes moche marcaron sus adobes y los chimú no, sugiero que los fabricantes de adobes moche no estuvieron tan cercanamente supervisados como los fabricantes de adobes chimú. Con las marcas de los fabricantes, un funcionario del Estado moche no estaba obligado a visitar los talleres de adobe y supervisar la producción de adobes, y podían entonces (1) recibir los adobes en el lugar de la construcción, (2) identificar el fabricante y transportador de los adobes y (3) asegurarse de que cada grupo de trabajadores completaran la construcción de cada unidad usando los 


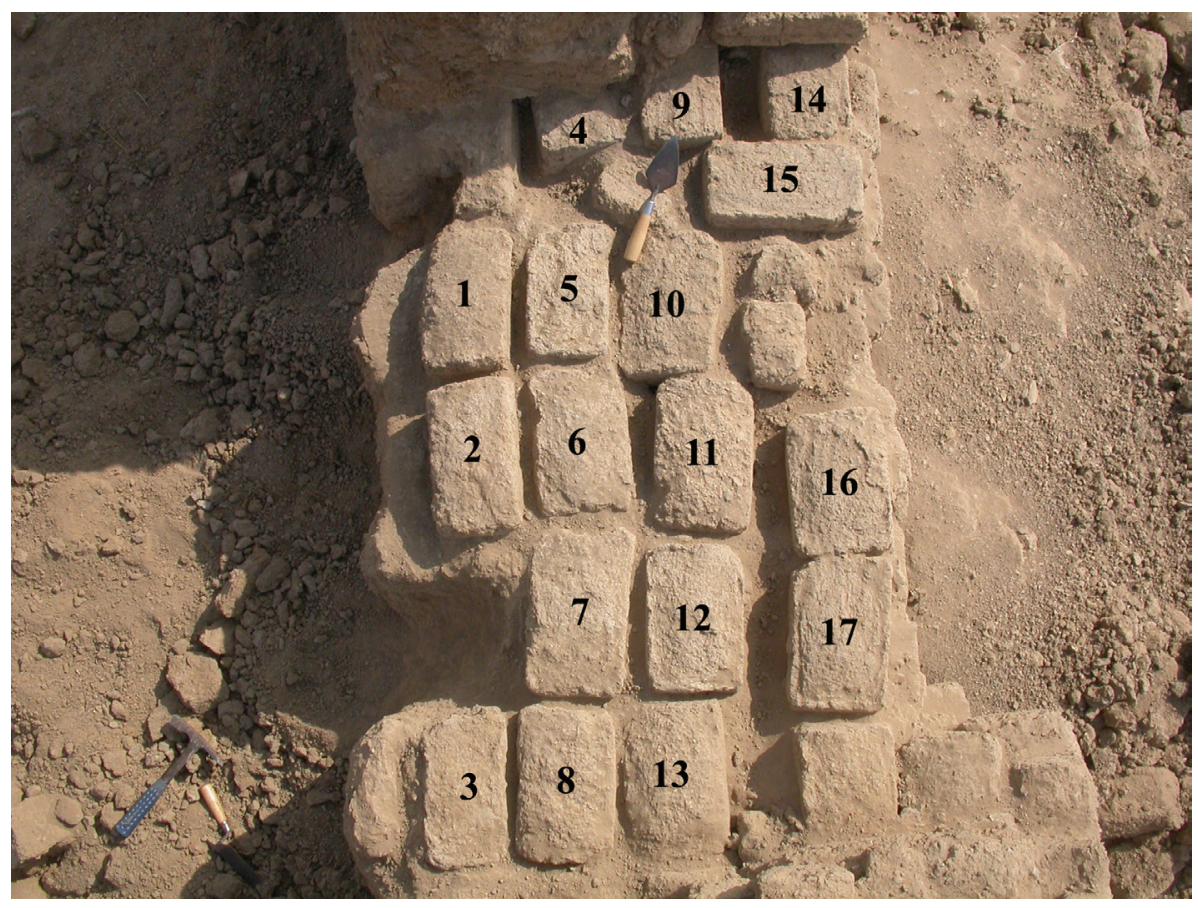

Figura 18. Adobes de la Capa 5 del Corte 3, Complejo II, Farfán. Los números en los adobes corresponden a la Tabla 10. El badilejo (encima del Adobe 10) apunta hacia el norte.

adobes producidos en su misma comunidad (y que no "tomaran prestados" accidentalmente los adobes de otras). Si los funcionarios del Estado hubieran supervisado cada una de las fases de la producción y construcción, entonces las marcas de los fabricantes no hubieran sido necesarias para dar cuenta del trabajo realizado. Y esto es lo que creo que los administradores chimú hicieron: reemplazaron las marcas del fabricante, consideradas como especie de "recibos" o "tarjeta de ponchar" de trabajo, por una supervisión y monitoreo más directo.

Esta diferencia entre los métodos de supervisión de los moche y los chimú puede ser debido a (1) la distancia entre el área de la producción de adobe y el área de la construcción o (2) el grado de centralización de cada Estado. Primero, si la manufactura de adobes de los chimú ocurrió cerca del lugar de la construcción, los funcionarios chimú podían observar qué comunidades estaban manufacturando los adobes y a la vez supervisar la construcción. Por el contrario, si en el caso de los moche la manufactura de los adobes ocurría lejos de las pirámides, entonces los funcionarios moche no podían supervisar la producción de adobes. En vez de ello, esperaban en el lugar de la construcción, recibían los adobes y acreditaban el trabajo hecho a cada comunidad al examinar las marcas de los fabricantes en el adobe. 


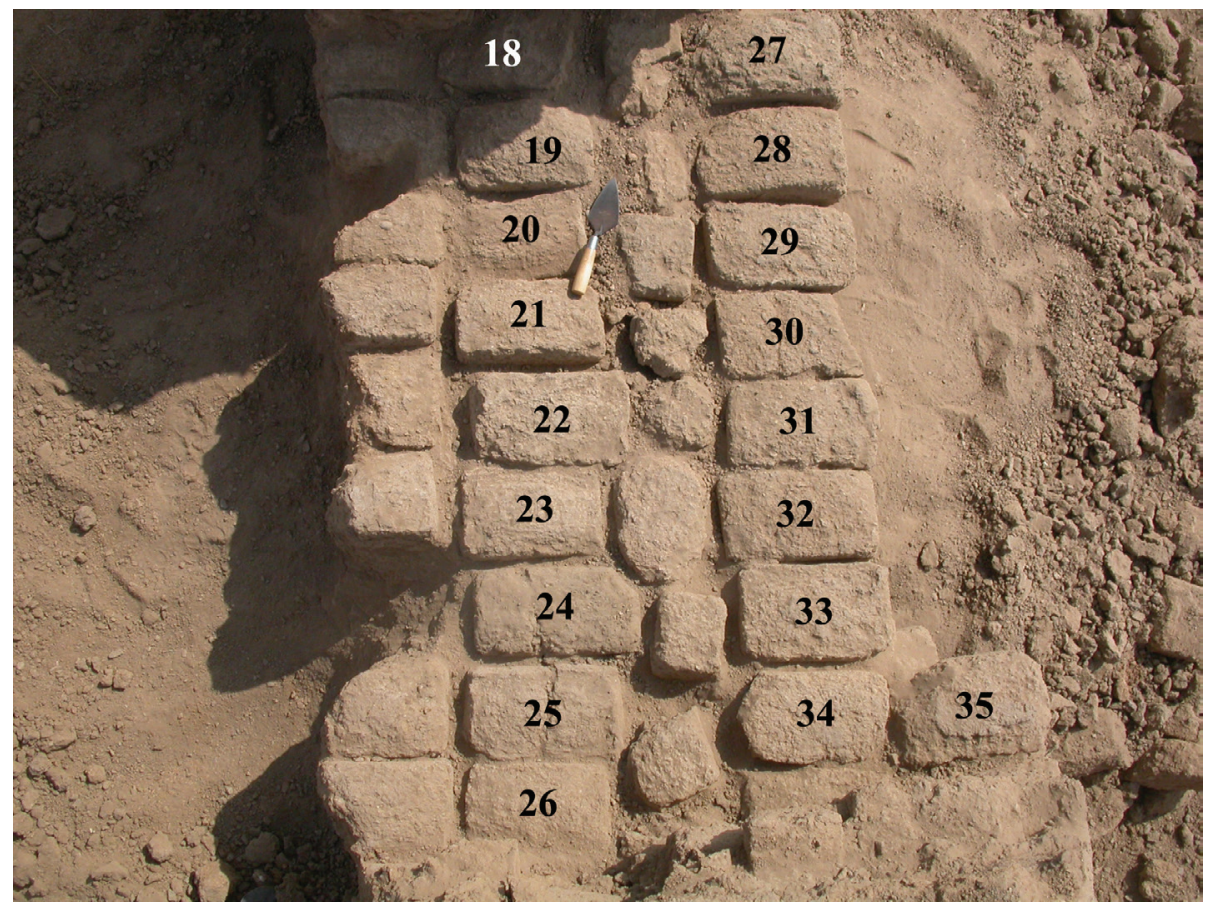

Figura 19. Adobes de la Capa 6 del Corte 3, Complejo II, Farfán. El badilejo apunta hacia el norte. Los números en los adobes corresponden a la Tabla 10. Observe el uso de adobes rotos como relleno.

Es posible que bajo los chimú, grupos de fabricantes de adobes y albañiles especializados estuvieran directamente bajo el control de señores locales, quienes estaban a su vez subordinados al Estado chimú. En este sistema especializado, cada grupo de fabricantes de adobes y albañiles se convirtió en una unidad de pago de tributo laboral, y debido a que el Estado ya no estaba manteniendo un historial del tributo que pagaba cada comunidad, el resultado fue la aparición de adobes de diferentes formas y tamaños en una misma sección de una pared o una misma edificación. Esto contrasta con el sistema moche, en el que cada unidad de tributo estaba constituida por una comunidad o ayllu. Cada ayllu tenía sus respectivos fabricantes de adobes y albañiles, y para los moche era importante separar el tributo de cada ayllu. Los especialistas en la construcción, los albañiles, fueron documentados en los testimonios españoles del siglo XVI de la costa norte del Perú (Ramírez 1986, tabla 11.1). Aunque aún no queda claro si el término albañil que aparece en los documentos lo usaban para referirse a fabricantes de adobes, albañiles o ambos, ese tipo de especialización puede haberse originado durante el periodo Intermedio Tardío. Quizás trabajaban en proyectos estatales durante algunos meses, pagando un impuesto en trabajo similar al que impusieron los incas (LeVine 1987, 24). 


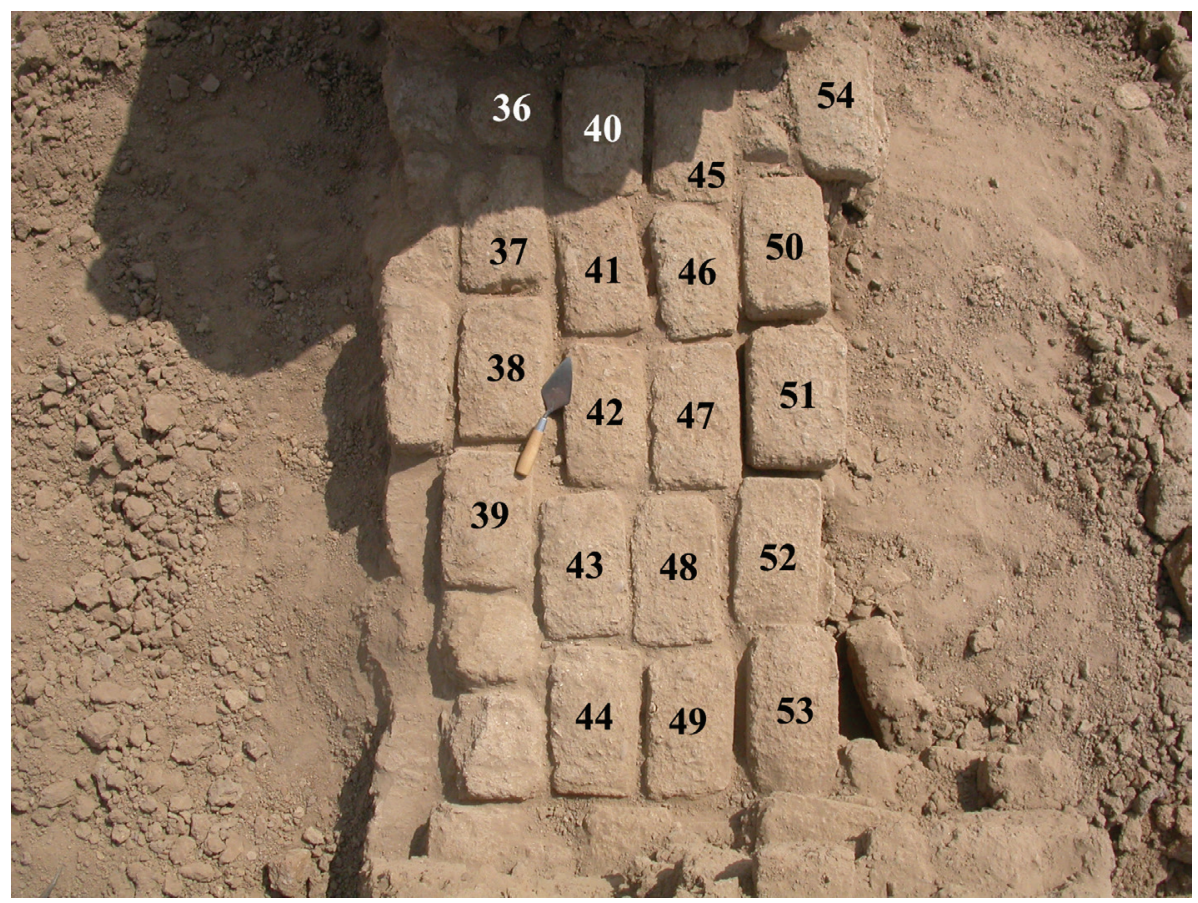

Figura 20. Adobes de la Capa 7 del Corte 3, Complejo II, Farfán. El badilejo apunta hacia el norte. Los números en los adobes corresponden a la Tabla 10. Observe que el Adobe 51 es levemente más ancho que los adobes adyacentes.

El patrón de construcción de adobe de Sicán, como fue documentado por Cavallaro y Shimada (1988), puede representar un momento intermedio entre los Gobiernos moche y chimú: igual que los moche, la producción de adobe de Sicán ocurrió en un lugar diferente al de la construcción, y por ende requería tener marcas de los fabricantes. Sin embargo, el sistema de construcción de Sicán era uno especializado (como el sistema chimú), que conllevaba grupos separados de fabricantes de adobes y albañiles, y, por lo tanto, resultó en el tipo de mezcla de adobes diferentes vistos en Farfán (tabla 11). Así pues, propongo que el modelo de impuestos cobrados a través de tareas realizadas elaborado por Shimada (Modelo B en la fig. 3) es el que mejor describe las formas de organizar la mano de obra en Sicán y Chimú, mientras que en el caso de los moche la organización de la mano de obra es mejor explicada por el modelo de tareas realizadas descrito por Moseley (Modelo A en la fig. 3).

La hipótesis que he propuesto puede ser probada de varias maneras. Primero, cuando diferentes comunidades se unen para construir un monumento grande, yo esperaría ver algún tipo de división que distinga la construcción de un segmento de otro. En este caso, necesitamos más datos sobre los adobes de los sitios construidos en el periodo entre las edificaciones de la Huaca de 


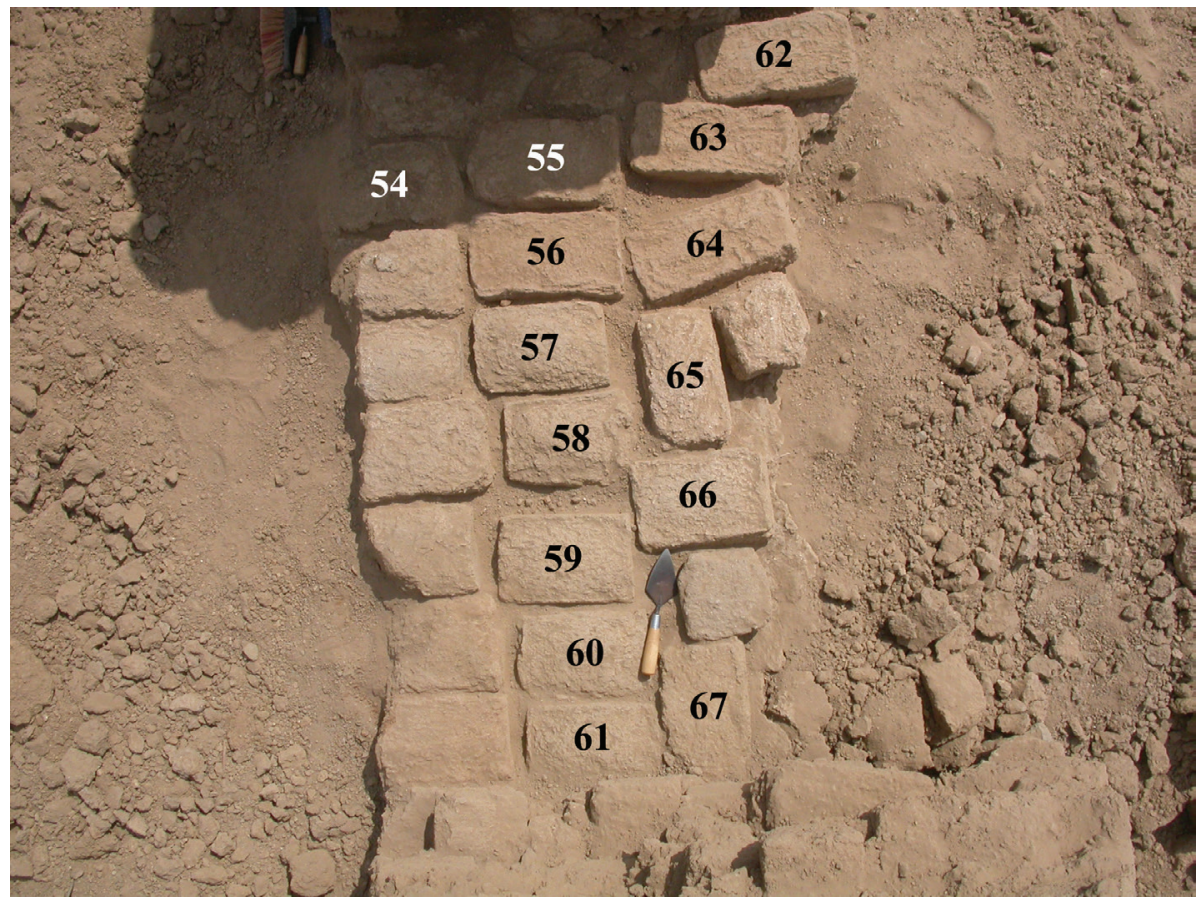

Figura 21. Adobes de la Capa 8 del Corte 3, Complejo II, Fafán. El badilejo apunta hacia el norte. Los números en los adobes corresponden a la Tabla 10. Observe que los Adobes 62-64 son levemente más largos y más angostos que los demás adobes.

la Luna y Farfán, para poder entender en mayor detalle la relación entre los monumentos, las técnicas de construcción y la segmentación. Supondría que mientras las estructuras se volvían más heterogéneas dentro de un lugar específico, teniendo más y diversos elementos arquitectónicos (depósitos, plataformas, bancos, rampas, corredores), habría menor necesidad de tener segmentos desconectados, porque cada elemento individual construido sería una unidad de impuesto pagado en trabajo.

Segundo, mientras el lugar de la producción de adobes se mueve cada vez más lejos del lugar de la edificación, los oficiales estatales pueden visitar cada uno de los talleres de adobes (lo que toma bastante tiempo) o permanecer en el lugar de la construcción, asegurándose que suficientes adobes sean transportados a la zona. En el caso de los moche, las marcas de los fabricantes fueron utilizadas para ayudar a los oficiales a documentar la producción de adobes. Investigaciones futuras deberán probar mis interpretaciones mediante la investigación del suelo usado para la construcción de los adobes moche y chimú. Esperaría encontrar que los adobes moche fueron hechos de suelo lejano al área de la construcción del monumento, y los adobes chimú de suelo cercano a los complejos rectangulares. 


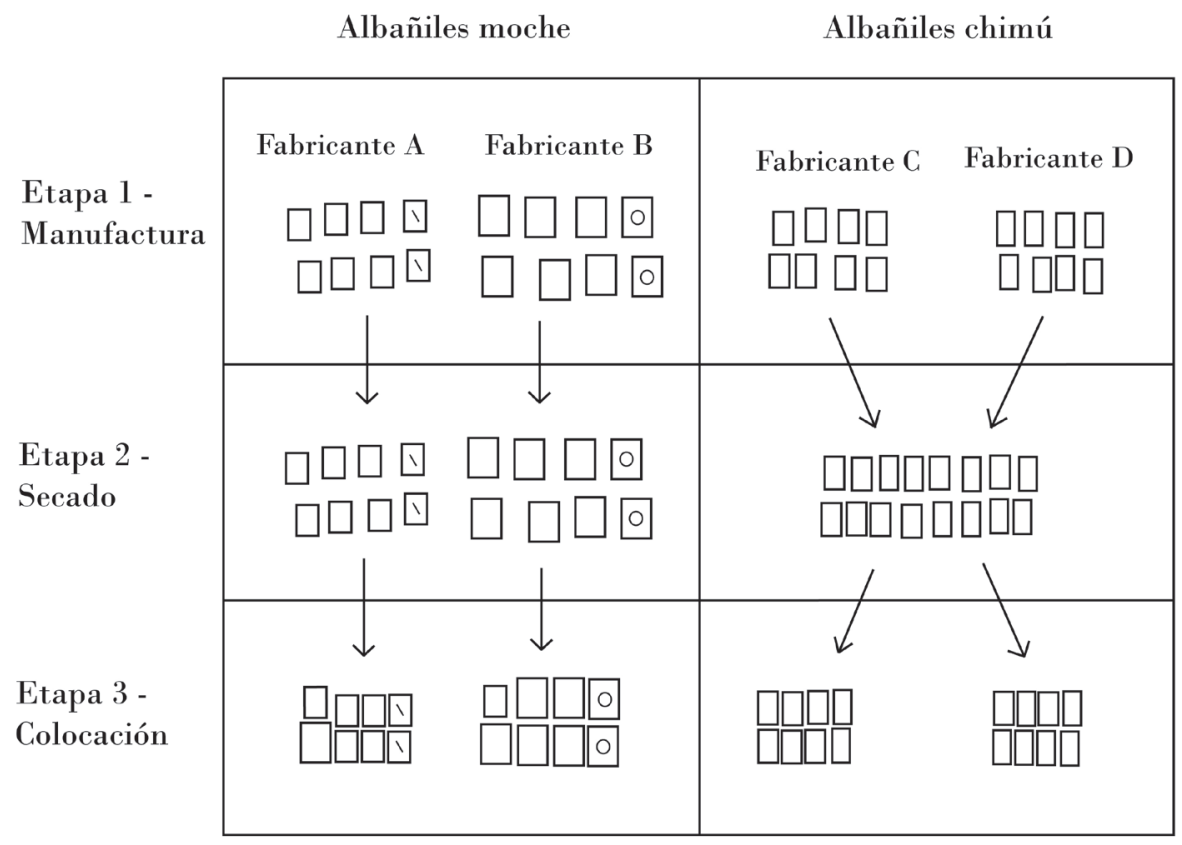

Figura 22. Diagrama hipotético comparando las tres etapas del proceso de manufactura, secado y colocación de adobes utilizadas por los albañiles moche y chimú.

Finalmente, anticipo que un Estado mucho más centralizado tendría formas de organización laboral diferentes a Estados mucho menos centralizados. Para probar esta hipótesis, necesitamos otro tipo de evidencia para determinar cuánto control el Estado tenía sobre la producción. La evidencia arqueológica necesaria para probar el control centralizado sobre la producción y distribución incluiría la cerámica o la metalurgia, y elementos administrativos como las audiencias y los depósitos. De hecho, investigadores trabajando en la costa norte del Perú ya han propuesto que el Estado chimú fue uno más centralizado, con control burocrático más grande sobre la mano de obra y los recursos que los Estados moche (J. Topic 2003; T. Topic 1982, 282-283). Podríamos extender esta línea investigativa a los valles costeños fuera del corazón de la cultura moche, como Nepeña, Casma y Huarmey.

\section{CONCLUSIÓN}

Kroeber $(1930,61)$ sugirió que, durante la construcción de las "edificaciones chimú", "cada contingente de una comunidad" había construido "su propia pa- 
Tabla 11. Comparación de los procesos hipotéticos de técnicas constructivas entre las culturas moche, sicán y chimú.

\begin{tabular}{|c|c|c|c|}
\hline & Manufactura de adobes & Secado & Colocación \\
\hline $\begin{array}{l}\text { Moche } \\
\text { (d. C. 100-800) }\end{array}$ & $\begin{array}{l}\text { Marcas de fabricantes } \rightarrow \\
\text { producción no fue super- } \\
\text { visada. }\end{array}$ & Áreas separadas & $\begin{array}{l}\text { Misma marca para } \\
\text { un segmento. } \\
\text { Por lo tanto, } \\
\text { los fabricantes } \\
\text { de adobes } \\
\text { provenían } \\
\text { de la misma } \\
\text { comunidad de } \\
\text { los albañiles } \\
\text { responsables } \\
\text { por un solo } \\
\text { segmento. }\end{array}$ \\
\hline $\begin{array}{l}\text { Sicán } \\
\text { (Medio y Tardío, } \\
\text { d. C. 900-1375) }\end{array}$ & $\begin{array}{l}\text { Marcas de fabricantes } \rightarrow \\
\text { producción no fue super- } \\
\text { visada. }\end{array}$ & $\begin{array}{l}\text { Adobes juntados en } \\
\text { un área }\end{array}$ & $\begin{array}{l}\text { Mezcla de tama- } \\
\text { ños y marcas de } \\
\text { fabricantes. Los } \\
\text { albañiles son } \\
\text { diferentes a los } \\
\text { fabricantes. } \\
\text { Mezcla de } \\
\text { tamaños. Los }\end{array}$ \\
\hline $\begin{array}{l}\text { Chimú } \\
\text { (d. C. 900-1470) }\end{array}$ & $\begin{array}{l}\text { Sin marcas de fabricantes } \\
\rightarrow \text { producción fue super- } \\
\text { visada. }\end{array}$ & $\begin{array}{l}\text { Adobes juntados en } \\
\text { un área }\end{array}$ & $\begin{array}{l}\text { albañiles son } \\
\text { diferentes de } \\
\text { los fabricantes. }\end{array}$ \\
\hline
\end{tabular}

red o columna”. También mencionó la diferencia entre el norte y sur del Perú: "la mayoría de las edificaciones chimú aparentan haber sido mayormente creadas como unidades en vez de ser concretadas gradualmente, lo que es usualmente el caso en el centro y sur del Perú" (ibíd.). El estudio de la construcción de adobe y su relación a la organización de trabajo en la costa norte del Perú fue continuado por Hastings y Moseley (1975), Kolata (1978), Cavallaro y Shimada (1988) y Moubarac (2002).

El modelo de Moseley (1975) es muchas veces citado en resúmenes sobre la sociedad moche (Bawden 1996, 104-105; Stone-Miller 1995, 90-91; Wilson 1999, 387), pero muchos académicos que trabajan en los Andes no conocen que las marcas de los fabricantes no fueron usadas en los sitios arqueológicos tardíos como Chan Chan, o que hay una diversidad de marcas de fabricantes y tamaños de adobes en un mismo segmento de una pirámide en Sicán. Cambios subsecuentes en la producción y construcción de adobe en los Estados como Sicán y Chimú reflejan la reestructuración de cómo se organizaba el trabajo por Estados de segunda o tercera generación en la costa norte del Perú.

Sugiero que en Farfán, funcionarios chimú supervisaron el proceso completo de la producción y construcción de adobe. Debido a que los funcionarios 
chimú podían observar y hacer escrutinio del número de adobes fabricados por cada comunidad, las marcas de los fabricantes u otras maneras de documentar el trabajo no eran necesarias. Sin embargo, los oficiales estatales moche no supervisaban la producción de adobes. Las comunidades locales fabricaban los adobes lejos del lugar de la construcción y fuera de la supervisión de los funcionarios. Así, los talleres de adobe moche marcaron sus adobes para asegurarse de recibir el crédito por su trabajo. Funcionarios estatales moche recibían los adobes en el lugar de la construcción y supervisaban la construcción de la edificación.

A pesar de los $100 \mathrm{~km}$ de distancia y el intervalo de 700 años entre la Huaca de la Luna y Farfán, no hay ninguna razón a priori para asumir que los métodos de construcción en ambos lugares fueron iguales o diferentes. No es adecuado (o certero; véase T. Topic 1982, 280-282) referirse a los chimú como otro grupo "étnico" para explicar sus diferencias con los moche, ya que debemos de tomar en cuenta los orígenes de los principios de la producción y la construcción de adobe chimú, o cualquier otra práctica cultural chimú, los cuales, como cualquier rasgo cultural, no emergieron de la nada. Para llenar esta laguna en nuestros datos, recomiendo continuar el estudio presente, investigando la organización de trabajo en los valles desde Jequetepeque a Moche y abarcando desde el periodo Intermedio Temprano al Horizonte Tardío. Una investigación sobre la construcción de adobe y la organización de trabajo de dicha larga duración ha sido iniciada en la región de Lambayeque (Shimada 1997).

Estudios futuros sobre la variabilidad del adobe deberán medir una muestra adecuada de adobes de diversas partes de cada lugar y documentar la localidad exacta de los mismos. Se necesita medir muchos más adobes in situ, especialmente en la Huaca de la Luna. Deberíamos también recolectar información similar de otros sitios de diferentes valles y periodos. Tschauner (2001, 787809) ha medido adobes en diversos sitios en la región de Lambayeque y Reindel (1993) ha estudiado la arquitectura de varios sitios en la costa norte del Perú, aunque en ambos estudios falta una comparación detallada de datos de adobes dentro de un mismo sitio. Debido a que "varias formas de adobes coexisten en tiempo y espacio" (Shimada 1990, 355), es importante medir una muestra adecuada de adobes. A menos que los adobes sean perfectamente iguales, las dimensiones de los adobes variarán a través del mismo espacio. Mi recomendación es tomar muestras de adobes de diferentes partes del sitio, que incluyan al menos 100 adobes de cada parte, para poder evaluar la variabilidad a través del espacio. También sugiero investigar dicha variabilidad a través del tiempo (en otras palabras, a través de diversos periodos culturales), lo que requerirá que el investigador conozca cuándo fueron construidas las diferentes partes del sitio. Por ejemplo, sería interesante estudiar adobes en lugares que datan del Horizonte Tardío para ver si la organización de trabajo había cambiado bajo la administración inca. 
Para entender la variabilidad de los adobes en un mismo sitio, se deben hacer cortes de muestreo de adobe, como las hechas en este estudio. El investigador debe abrir secciones de la arquitectura, observar los métodos de construcción y documentar las dimensiones de los adobes in situ. Documentar los adobes in situ permitirá al investigador detectar la presencia (o ausencia) de segmentos de construcción vertical u horizontal. Más aún, se debe tratar de observar las diferencias de los adobes en segmentos horizontales y verticales, la naturaleza de la diferencia, y qué nos pueden decir sobre la organización de trabajo.

Smith $(2004,92)$ notó las dificultades que enfrentan los arqueólogos cuando intentan estudiar la organización de trabajo. Sugiero que el análisis de las unidades de construcción, como bloques de piedra y adobes, puede ayudarnos a entender cómo comunidades o funcionarios estatales organizaron la mano de obra. En la costa norte del Perú, la desaparición de las marcas de fabricantes significa que, en el nivel más básico de interpretación, el Estado chimú documentó el trabajo de formas diferentes a como lo hizo el Estado moche. Por lo tanto, la organización de la mano de obra en los Andes no fue un proceso monolítico ni estático, sino un fenómeno dinámico que varió a través del tiempo y espacio.

Es posible que el Estado chimú o el Estado moche organizara el trabajo de formas diferentes para la realización de distintas tareas, como la construcción de monumentos, la limpieza de los canales, la producción de cerámica, etc. Para poder comprender la diversidad de la organización de trabajo, debemos documentar la movilización de la misma en sitios diferentes, contextos diferentes (construcción de monumentos, producción de cerámica, etc.), y en regiones y periodos diferentes. Sólo entonces podremos comenzar a entender la relación entre el tipo de organización de trabajo y la naturaleza del sistema socio-político.

\section{AGRADECIMIENTOS}

Esta investigación recibió financiamiento de la Beca de Investigación Graduada (Graduate Research Fellowship) de la Fundación Nacional para la Ciencia (National Science Foundation) de los Estados Unidos, y apoyo adicional del Instituto Internacional y el Departamento de Antropología de la Universidad de Michigan. Agradezco a Carol Mackey y a Santiago Uceda por tan generosamente haberme permitido recolectar datos de los adobes en Farfán y la Huaca de la Luna. Estoy muy agradecido a Raffael Cavallaro, Claude Chapdelaine, Robyn Cutright, Tom Dillehay, Cameron Gokee, Carol Mackey, Michael Moseley, John O’Shea, Jeff Parsons, Kenny Sims, Charles Stanish, Henry Wright y otros lectores anónimos por los comentarios y sugerencias sobre los borra- 
dores iniciales de este artículo. Agradezco a Carol Mackey, César Jáuregui y Enrique Zavaleta por su dirección y apoyo durante mi trabajo de campo en la Huaca de la Luna y Farfán. Mis más profundos agradecimientos para Joyce Marcus por su estímulo y ayuda, sin los cuales la publicación de este trabajo no hubiera sido posible.

A esta lista de distinguidos investigadores quisiera incluir dos colegas más - Juan Hernández García y Lenny Ureña Valerio - por su meticuloso y astuto trabajo de traducción y revisión de la versión en español de este artículo. Les doy mis sinceras gracias.

\section{REFERENCIAS}

Andrews, Anthony P. 1974. "The U-Shaped Structures at Chan Chan, Peru”. Journal of Field Archaeology 1 (3/4): 241-264.

Bawden, Garth. 1996. The Moche. Cambridge, MA: Blackwell.

Billman, Brian R. 2002. "Irrigation and the Origins of the Southern Moche State on the North Coast of Peru". Latin American Antiquity 13 (4): 371-400.

Brown, Paul Wencil, y James R. Clifton. 1978. "Adobe I: The Properties of Adobe". Studies in Conservation 23 (4): 139-146.

Cabello Valboa, Miguel. (1586) 1951. Miscelánea antártica: Una historia del Perú antiguo. Lima: Instituto de Etnología, Universidad Nacional Mayor de San Marcos.

Calancha, Antonio de la. (1639) 1977. Corónica moralizada del orden de San Agustín en el Perú. Vol. 4. Lima: Universidad Nacional Mayor de San Marcos.

Castillo, Luis Jaime, y Christopher B. Donnan. 1994. "Los mochica del norte y los mochica del sur". En Vicús, editado por Krzysztof Makowski, Christopher B. Donnan, Iván Amaro Bullón, Luis Jaime Castillo, Magdalena Diez Canseco, Otto Eléspuru Revoredo y Juan A. Murro Mena, 143-176. Lima: Banco de Crédito del Perú.

Cavallaro, Raffael. 1991. Large-Site Methodology: Architectural Analysis and Dual Organization in the Andes. Occasional Papers 5. Calgary: Department of Archaeology, University of Calgary.

Cavallaro, Raffael, y Izumi Shimada. 1988. "Some Thoughts on Sican Marked Adobes and Labor Organization”. American Antiquity 53 (1): 75-101.

Chapdelaine, Claude. 2000. "Struggling for Survival: The Urban Class of the Moche Site, North Coast of Peru”. En Environmental Disaster and the Archaeology of Human Response, editado por Garth Bawden y Richard Martin Reycraft, 121-142. Albuquerque: Maxwell Museum of Anthropology, University of New Mexico. . 2001. "The Growing Power of a Moche Urban Class". En Moche Art and Archaeology in Ancient Peru, editado por Joanne Pillsbury, 68-87. New Haven: Yale University Press.

. 2003. "La ciudad de Moche: Urbanismo y estado". En Moche: Hacia el final del milenio. Tomo II, editado por Santiago Uceda y Elías Mujica, 247-285. Lima: Pontificia Universidad Católica del Perú.

Collier, Donald. 1955. Cultural Chronology and Change as Reflected in the Ceramics of the Virú Valley. Fieldiana Anthropology, vol. 43, no. 1. Chicago: Chicago Natural History Museum. 
Conlee, Christina A., Jalh Dulanto, Carol J. Mackey y Charles Stanish. 2004. "Late Prehispanic Sociopolitical Complexity”. En Andean Archaeology, editado por Helaine Silverman, 209-236. Malden, MA: Blackwell.

Conrad, Geoffrey W. 1990. "Farfan, General Pacatnamu, and the Dynastic History of Chimor". En The Northern Dynasties: Kingship and Statecraft in Chimor, editado por Michael E. Moseley y Alana Cordy-Collins, 227-242. Washington, DC: Dumbarton Oaks Research Library and Collection.

Cordy-Collins, Alana. 1990. "Fonga Sigde, Shell Purveyor to the Chimor King”. En The Northern Dynasties: Kingship and Statecraft in Chimor, editado por Michael E. Moseley y Alana Cordy-Collins, 393-417. Washington, DC: Dumbarton Oaks Research Library and Collection.

Day, Kent C. 1982a. "Storage and Labor Service: A Production and Management Design for the Andean Area". En Chan Chan: Andean Desert City, editado por Michael E. Moseley y Kent C. Day, 333-349. Albuquerque: University of New Mexico Press.

. 1982b. "Ciudadelas: Their Form and Function". En Chan Chan: Andean Desert City, editado por Michael E. Moseley y Kent C. Day, 55-66. Albuquerque: University of New Mexico Press.

Donnan, Christopher B. 2007. Moche Tombs at Dos Cabezas. Monograph 59. Los Angeles: UCLA Cotsen Institute of Archaeology.

Donnan, Christopher B., y Carol J. Mackey. 1978. Ancient Burial Patterns of the Moche Valley, Peru. Austin: University of Texas Press.

Franco, Régulo, César Gálvez y Segundo Vásquez. 1994. "Arquitectura y decoración mochica en la Huaca Cao Viejo, Complejo El Brujo: Resultados preliminares”. En Moche: Propuestas y perspectivas, editado por Santiago Uceda y Elías Mujica, 147180. Lima: l'Institut Français d'Études Andines.

Fraser, Valerie. 1990. The Architecture of Conquest: Building in the Viceroyalty of Peru, 1535-1635. Cambridge: Cambridge University Press.

Gillin, John P. 1947. Moche: A Peruvian Coastal Community. Institute of Social Anthropology Publication, no. 3. Washington, DC: Smithsonian Institution.

Hastings, C. Mansfield, y M. Edward Moseley. 1975. “The Adobes of Huaca del Sol and Huaca de La Luna”. American Antiquity 40 (2): 196-203.

Heyerdahl, Thor, Daniel H. Sandweiss y Alfredo Narváez, ed. 1995. Pyramids of Túcume: The Quest for Peru's Forgotten City. New York: Thames and Hudson.

Keatinge, Richard W. 1982. “The Chimú Empire in a Regional Perspective: Cultural Antecedents and Continuities". En Chan Chan: Andean Desert City, editado por Michael E. Moseley y Kent C. Day, 197-224. Albuquerque: University of New Mexico Press.

Keatinge, Richard W., y Geoffrey W. Conrad. 1983. "Imperialistic Expansion in Peruvian Prehistory: Chimu Administration of a Conquered Territory". Journal of Field Archaeology 10 (3): 255-283.

Kolata, Alan L. 1978. "Chan Chan: The Form of the City in Time". Tesis doctoral, Harvard University. . 1982. "Chronology and Settlement Growth at Chan Chan". En Chan Chan: Andean Desert City, editado por Michael E. Moseley y Kent C. Day, 67-85. Albuquerque: University of New Mexico Press.

Kosok, Paul. 1965. Life, Land and Water in Ancient Peru. New York: Long Island University Press. 
Kroeber, Alfred L. 1930. Archaeological Explorations in Peru, Part II: The North Coast. Chicago: Field Museum of Natural History.

Lechtman, Heather. 1976. "A Metallurgical Site Survey in the Peruvian Andes". Journal of Field Archaeology 3 (1): 1-42.

LeVine, Terry Yarov. 1987. "Inka Labor Service at the Regional Level: The Functional Reality”. Ethnohistory 34 (1): 14-46.

Lockard, Gregory D. 2008. "A New View of Galindo: Results of the Galindo Archaeological Project”. En Arqueología mochica: Nuevos enfoques, editado por Luis Jaime Castillo Butters, Hélène Bernier, Gregory D. Lockard y Julio Rucabado Yong, 275294. Lima: Pontificia Universidad Católica del Perú.

Mackey, Carol J. 2003. "La transformación socioeconómica de Farfán bajo el gobierno inka”. En Identidad y transformación en el Tawantinsuyu y en los Andes coloniales. Perspectivas arqueológicas y etnohistóricas. Segunda parte, editado por Peter Kaulicke, Gary Urton y Ian Farrington, 321-353. Lima: Pontificia Universidad Católica del Perú.

. 2004. "La ocupación de dos centros administrativos en el valle de Jequetepeque: El Algarrobal de Moro y Farfán”. En Desarrollo arqueológico costa norte del Perú, editado por Luis Valle Alvarez, 75-88. Trujillo, Perú: Sián.

.2006. "Elite Residences at Farfán: A Comparison of the Chimú and Inka Occupations". En Palaces and Power in the Americas: From Peru to the Northwest Coast, editado por Jessica Joyce Christie y Patricia Joan Sarro, 313-352. Austin: University of Texas Press.

. 2009. "Chimú Statecraft in the Provinces". En Andean Civilization: A Tribute to Michael E. Moseley, editado por Joyce Marcus y Patrick Ryan Williams, 325-349. Los Angeles: Cotsen Institute of Archaeology, University of California.

Mackey, Carol J., y César Jáuregui. 2001. Informe Preliminar de Proyecto Arqueológico Farfán. Lima: Instituto Nacional de Cultura, Perú. . 2004. Informe Preliminar de Proyecto Arqueológico Farfán. Lima: Instituto Nacional de Cultura, Perú.

McClelland, Donald H. 1986. "Brick Seriation at Pacatnamu”. En The Pacatnamu Papers, editado por Christopher B. Donnan y Guillermo A. Cock, 27-46. Los Angeles: UCLA Museum of Cultural History.

Meneses, Susana, y Luis Chero. 1994. "La arquitectura”. En Sipán: Descubrimiento e investigación, editado por Walter Alva, 181-188. Lima: Walter Alva.

Moore, Jerry D., y Carol J. Mackey. 2008. “The Chimú Empire”. En The Handbook of South American Archaeology, editado por Helaine Silverman y William H. Isbell, 783-807. New York: Springer.

Morales, Ricardo. 2003. "Iconografía litúrgica y contexto arquitectónico en Huaca de la Luna, valle de Moche”. En Moche: Hacia el final del milenio. Tomo I, editado por Santiago Uceda y Elías Mujica, 425-476. Lima: Pontificia Universidad Católica del Perú.

Moseley, M. Edward. 1975. "Prehistoric Principles of Labor Organization in the Moche Valley, Peru”. American Antiquity 40 (2): 191-196.

Moseley, Michael E. 2001. The Incas and Their Ancestors: The Archaeology of Peru. 2. ${ }^{\mathrm{a}}$ ed. London: Thames and Hudson.

Moubarac, Jean-Claude. 2002. "La production d'adobes dans l'ancienne capitale de létat Moche, société précolombienne de la côte nord du Pérou”. Tesis de maestría, Université de Montréal. 
Munsell Color. 2000. Munsell Soil Color Charts. New Windsor, CT: Munsell Color.

Pérez, Ismael. 1994. "Notas sobre la denominación y estructura de una huaca mochica en Florencia de Mora, valle de Moche". En Moche: Propuestas y Perspectivas, editado por Santiago Uceda y Elías Mujica, 223-250. Lima: Institut Français d'Etudes Andines.

Pillsbury, Joanne. 1996. "The Thorny Oyster and the Origins of Empire: Implications of Recently Uncovered Spondylus Imagery from Chan Chan, Peru”. Latin American Antiquity 7 (4): 313-340.

Ramírez, Susan E. 1986. "Notes on Andean Exchange: A Plea for Collaboration”. En Andean Archaeology: Papers in Memory of Clifford Evans, editado por Ramiro Matos Mendieta, Solveig A. Turpin y Herbert H. Eling Jr., 225-238. Los Angeles: UCLA Institute of Archaeology.

Reindel, Markus. 1993. Monumentale Lehmarchitektur an der Nordküste Perus: Eine repräsentative Untersuchung nach-formativer Grossbauten vom LambayequeGebiet bis zum Virú-Tal. Bonn: Holos.

Rowe, John H. 1946. "Inca Culture at the Time of the Spanish Conquest". En The Andean Civilizations, editado por Julian H. Steward, 183-330. Washington, DC: Smithsonian Institution.

Rowe, John H. 1948. "The Kingdom of Chimor". Acta Americana 6: 26-59.

Sandweiss, Daniel H. 1995. "Life in Ancient Túcume". En Pyramids of Túcume: The Quest for Peru's Forgotten City, editado por Thor Heyerdahl, Daniel H. Sandweiss y Alfredo Narváez, 142-168. New York: Thames and Hudson.

Shimada, Izumi. 1990. "Cultural Continuities and Discontinuities on the North Coast of Peru". En The Northern Dynasties: Kingship and Statecraft in Chimor, editado por Michael E. Moseley y Alana Cordy-Collins, 297-392. Washington, DC: Dumbarton Oaks Research Library and Collection.

Shimada, Izumi. 1994. Pampa Grande and the Mochica Culture. Austin: University of Texas Press.

Shimada, Izumi. 1997. "Organizational Significance of Marked Bricks and Associated Construction Features on the North Peruvian Coast”. En Arquitectura y civilización en los Andes prehispánicos, editado por Elisabeth Bonnier y Henning Bischof, 6289. Mannheim: Reiss Museum.

Shimada, Izumi. 2000. "The Late Prehispanic Coastal States". En The Inca World: The Development of Pre-Columbian Peru, A.D. 1000-1534, editado por Laura Laurencich Minelli, 49-110. Norman: University of Oklahoma Press.

Siegel, Sidney. 1956. Nonparametric Statistics for the Behavioral Sciences. New York: McGraw-Hill.

Smith, Michael E. 2004. “The Archaeology of Ancient State Economies”. Annual Review of Anthropology 33: 73-102.

Stanish, Charles. 2001. "The Origin of State Societies in South America”. Annual Review of Anthropology 30: 41-64.

Stone-Miller, Rebecca. 1995. Art of the Andes: From Chavin to Inca. London: Thames and Hudson.

Tello, Julio C. 2004. Arqueología de Cajamarca: La expedición al Marañon-1937. Lima: Universidad Nacional Mayor de San Marcos.

Thompson, Donald E., y John V. Murra. 1966. “The Inca Bridges in the Huánuco Region”. American Antiquity 31 (5): 632-639.

Topic, John R. 2003. "From Stewards to Bureaucrats: Architecture and Information Flow at Chan Chan, Peru". Latin American Antiquity 14 (3): 243-274. 
Topic, John R., y Michael E. Moseley. 1983. "Chan Chan: A Case Study of Urban Change in Peru”. Nawpa Pacha 21: 153-182.

Topic, Theresa Lange. 1982. "The Early Intermediate Period and Its Legacy”. En Chan Chan: Andean Desert City, editado por Kent C. Day y Michael E. Moseley, 255284. Albuquerque: University of New Mexico Press.

Tschauner, Hartmut. 2001. "Socioeconomic and Political Organization in the Late Prehispanic Lambayeque Sphere, Northern North Coast of Peru”. Tesis doctoral, Harvard University.

Tufinio, Moisés. 2003. “Plaza 2B”. En Proyecto Arqueológico Huaca de la Luna: Informe técnico 2002, editado por Santiago Uceda y Ricardo Morales, 27-36. Trujillo, Perú: Facultad de Ciencias Sociales, Universidad Nacional de Trujillo.

Uceda, Santiago. 1997. "Huaca de la Luna: La arquitectura y los espacios ceremoniales". Arkinka 20: 104-112.

.2001. "Investigations at Huaca de la Luna, Moche Valley: An Example of Moche Religious Architecture". En Moche Art and Archaeology in Ancient Peru, editado por Joanne Pillsbury, 46-67. New Haven: Yale University Press.

Uceda, Santiago, y José Armas. 1997. "Los talleres alfareros en el centro urbano Moche”. En Investigaciones en la Huaca de la Luna 1995, editado por Santiago Uceda, Elías Mujica y Ricardo Morales, 93-104. Trujillo, Perú: Facultad de Ciencias Sociales de la Universidad Nacional de La Libertad.

Uceda, Santiago, y Claude Chapdelaine. 1998. "El centro urbano de las Huacas del Sol y la Luna”. Arkinka 33: 94-103.

Uceda, Santiago, Ricardo Morales, José Canziani y María Montoya. 1994. “Investigaciones sobre la arquitectura y relieves polícromos en la Huaca de la Luna, valle de Moche". En Moche: Propuestas y perspectivas, editado por Santiago Uceda y Elías Mujica, 251-303. Lima: Institut Français d'Études Andines.

Uceda, Santiago, y Moisés Tufinio. 2003. “El complejo arquitectónico religioso moche de Huaca de la Luna: Una aproximación a su dinámica ocupacional”. En Moche: Hacia el final del milenio. Tomo II, editado por Santiago Uceda y Elías Mujica, 179-228. Lima: Pontificia Universidad Católica del Perú.

Urton, Gary. 1988. "Arquitectura pública como texto social: La historia de un muro de adobe en Pacariqtambo, Perú (1915-1985)". Revista Andina 6 (1): 225-261.

Willey, Gordon R. 1953. Prehistoric Settlement Patterns in the Virú Valley, Perú. Bureau of American Ethnology Bulletin, no. 155. Washington, DC: Smithsonian Institution.

Wilson, David J. 1988. Prehispanic Settlement Patterns in the Lower Santa Valley, Peru: A Regional Perspective on the Origins and Development of Complex North Coast Society. Washington, DC: Smithsonian Institution Press. 1999. Indigenous South Americans of the Past and Present: An Ecological Perspective. Boulder, CO: Westview Press.

Zavaleta, Luis Enrique. 2007. "Investigaciones en la Unidad 16 de Huaca de la Luna". En Informe técnico 2006, Proyecto Arqueológico Huaca de la Luna, editado por Santiago Uceda y Ricardo Morales, 13-34. Trujillo, Perú: Facultad de Ciencias Sociales, Universidad de Trujillo. 